\title{
Experimental System of Hydrodynamic Action of Dunhuang Mogao Grottoes under Temperature-Humidity-Mechanical (THM) Coupling
}

\author{
Zhigang Tao $\mathbb{D}^{1,2}$ Huixia Xu $\mathbb{D}^{1,2}$ Hongzhen Peng, ${ }^{2}$ and Weixin Liu ${ }^{3}$ \\ ${ }^{1}$ State Key Laboratory for GeoMechanics and Deep Underground Engineering, Beijing, China \\ ${ }^{2}$ School of Mechanics and Civil Engineering, China University of Mining and Technology, Beijing, China \\ ${ }^{3}$ College of Science and Technology, Hebei University of Engineering, Handan, China
}

Correspondence should be addressed to Zhigang Tao; taozhigang@cumtb.edu.cn and Huixia Xu; zqt1800606135g@student.cumtb.edu.cn

Received 25 June 2020; Revised 14 August 2020; Accepted 28 August 2020; Published 22 September 2020

Academic Editor: Zongqing Zhou

Copyright ( 92020 Zhigang Tao et al. This is an open access article distributed under the Creative Commons Attribution License, which permits unrestricted use, distribution, and reproduction in any medium, provided the original work is properly cited.

In order to thoroughly investigate the weathering mechanism of the murals in Dunhuang Mogao Grottoes, based on the independently developed hydrodynamic test system of the surrounding rocks under the combined action of temperature, humidity, and stress, this study performed the liquid water adsorption test and gaseous water adsorption test of the surrounding rocks of the support body of Dunhuang Mogao Grottoes, as well as the softening test of the strength of liquid water adsorbed by the rock samples. The experimental results are as follows: (a) Q- $t$ curve and $\ln w-\ln t$ curve of the three types of black sandstone rock samples obtained by analyzing the nonpressure water absorption experiment data indicate that the $Q-t$ curve of the rock samples showed a similar trend with time, with the initial curve being steep and rapid increase in the water absorption; the double logarithmic curve of water absorption is convex and tends to be saturated. (b) The absorbing water softening test analysis was carried out for four types of siltstone specimens with intensity of pressure; bibulous rate was found to vary with time, and sample parameters such as compressive strength and elastic modulus decreased linearly with increasing water absorption at different times of uniaxial compression test. (c) Through the summer and winter and cave surrounding rock within the sample, the gas adsorption of water simulation was combined with the adsorption curve analysis, indicating that the adsorption characteristics of the surrounding rock and the correlation of larger sample depend on season. These research results provide a reliable theoretical basis and technical support for the protection of the murals in the Mogao Grottoes of Dunhuang and the prevention and control by salt damage.

\section{Introduction}

The murals in the Mogao Grottoes of Dunhuang contain important historical, scientific, and artistic values as well as are important historical and cultural heritage of China for thousands of years; even though it is located in an arid region, water poses a major threat to the preservation of rock mass in this heritage $[1,2]$. This study was conducted to investigate the effect of rainfall on rock erosion. Various damages have been diagnosed under natural and human factors; therefore, it is of great significance to study and investigate the corro- sion mechanism for the original site protection of Grotto murals. As an important part of Grotto murals, surrounding rock support is very important for the protection of murals to study the weathering mechanism [3-6]. Based on the literature reports [7-10] on the effect of temperature, humidity, water, $\mathrm{pH}$, microorganisms, plants, and animals of recognized factors on the Grottoes, many field and laboratory experimental methods have been developed to thoroughly study their effect on the Grottoes. In addition, in order to protect the Mogao Grottoes, a series of geophysical exploration, regional environmental regulation, and other measures 
such as engineering of sand control were carried out and found to play a positive role in the Mogao Grottoes weathering [11-13].

There are cross-cutting fissures, level fissures, longitudinal cracks, and unloading fissures distributed in cliff of Mogao Grottoes by the influence of tectonic movement, long-term weathering, and excavation of caves. The interaction and development among these fractures will directly affect the cave's surrounding rock's stability, and meanwhile, these fractures are also channel for migration of water and moisture [14]. The weathering of grotto surrounding rocks and the corrosion (or deterioration) of murals regularly occurred by a combination of multiple factors; therefore, studying the weathering of grotto surrounding rocks under the action of multifield coupling is extremely urgent.

The conventional sampling drill, geotechnical laboratory hydrological test system, and in situ test equipment and methods for geotechnical experiment system cannot meet the demand of protection of Grottoes, particularly cultural relics, under the existing limitations of geotechnical experimental method applied to the protection; therefore, nondestructive testing and simulation experiment were carried out to study the Grotto rock weathering and damage of murals by salt, and this development process led to significantly important research results [15-18]. Rock weathering is mainly a variety of physical, chemical, and biological processes that cause rock damage and changes [19-21]. A series of studies reported that the grotto surrounding rock weathering and mechanism of mural deterioration is principally affected by moisture [22-24]; therefore, it is of great significance to reveal the weathering regularity of grotto surrounding rocks under the action of water and investigate the corrosion mechanism of mural for better protection of grotto murals. The key scientific problem is reportedly the interaction between water and rock under a combination of different conditions $[25,26]$.

At present, the outstanding characteristic of the experimental investigation on the weathering mechanism of the Mogao Grottoes in Dunhuang is to carry out simulation experiment on the existing environment of cultural relics obtained from the field monitoring data. In literature [27], the main influencing factors temperature, relative humidity, and light in the simulation experiment, the temperature cycle change, ultraviolet irradiation, and exposure were used to simulate the corrosion of murals, indicating that salt crystallization played an extremely important role in the corrosion of murals.

The above research results provided abundant methods for analyzing the weathering mechanism of the surrounding rock and the damage of murals by salt, but the problems need to be solved urgently as follows:

(1) Due to lack of a multifield coupling experimental system to simulate the environment of cultural relic for protection, there are a few studies on the surrounding rock of the support body, because the objects of pigment and earth layer were the main studies for the protection of Dunhuang Mogao Grottoes [28]
(2) Dry-wet and freeze-thaw cycle are based on single factor of the traditional experimental research or in the case of lacking coupling effect of multiple factors in experimental methods and models through combination of experimental methods such as wind erosion experiment on samples with different degrees of freeze-thaw experiment

(3) There is no consensus on the quantitative relationship between various factors and weathering failure under multifield coupling, and the weathering theories and mechanisms need to be further studied

(4) In the response to these problems, relevant research and development have been carried for surrounding rock hydrological experiment system under the combined effect of temperature, humidity, and stress

\section{Analysis of Regional Geological Conditions of Dunhuang Grottoes}

2.1. Physical Geography. Mogao Grottoes, in the front of the Dangquan, east to Sanweishan, are located at the eastern foot of Mingsha Mountain, $25 \mathrm{~km}$ southeast of Dunhuang city and are the largest and most famous Buddhist art grottoes in China, also known as "thousand Buddha caves." Mogao Grottoes now contain 735 grottoes and 492 grottoes with sculptures and murals, distributed on the cliffs of Mingsha Mountain in three or four layers. The total length is approximately $1600 \mathrm{~m}$, and the total area of the murals is $\sim 45,000 \mathrm{~m}^{2}$ comprising more than 2,000 painted Buddha statues.

2.2. Regional Meteorological Characteristics. In the climate with dryness and less rain, mass evaporation temperature varies widely between day and night, and plenty of sunshine pertains to the typical drought in the warm temperate zone $[29,30]$ with the following specifications: average annual precipitation, $39.9 \mathrm{~mm}$; evaporation, $2,486 \mathrm{~mm}$; annual sunshine hours, $3,246.7 \mathrm{~h}$; average annual temperature, $9.4{ }^{\circ} \mathrm{C}$; highest monthly average temperature, $24.9^{\circ} \mathrm{C}$ (in July); mean minimum monthly temperature, $9.3^{\circ} \mathrm{C}$ (in January); extreme low temperature, $43.6^{\circ} \mathrm{C}$; minimum temperature, $28.5^{\circ} \mathrm{C}$; and annual average frostless period, 142 days.

The data pertaining to the annual rainfall recorded by the research institute of Dunhuang Mogao Grottoes in 2012 (Figure 1) indicate that the scare annual precipitation is mainly distributed from May to August approximately $150-240 \mathrm{~d}$ in the summer and occasional snowfall in the winter.

The temperature and humidity distribution characteristics were monitored and analyzed by the research institute of Dunhuang in 2012 (Figure 2), indicating that the annual minimum temperature was $-19^{\circ} \mathrm{C}$, and the highest atmospheric temperature was $33^{\circ} \mathrm{C}$. The hot and humid environment was particularly significant during the times of 150-180 d, especially from May until August. At the same time, the humidity showed obvious synchronous characteristics, and the effective range reached 3 to 5 days. 


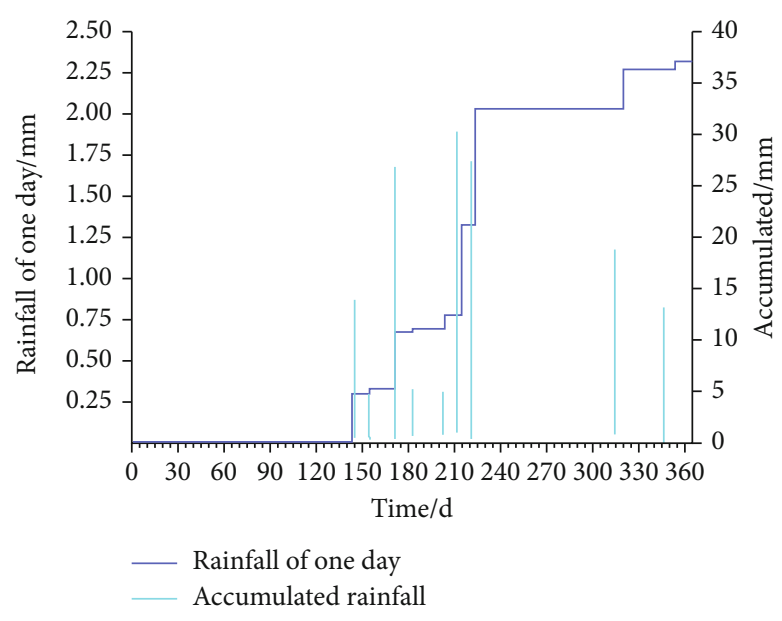

FIgUre 1: Mogao Grottoes annual rainfall trend.

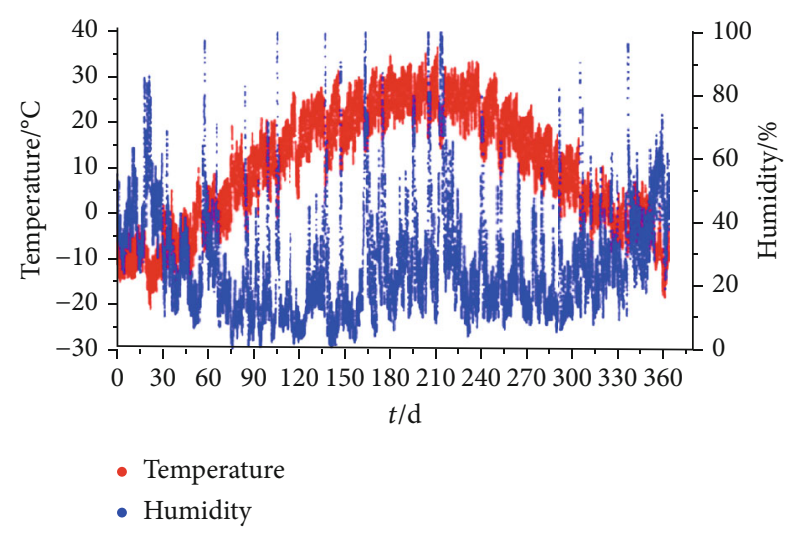

FIGURE 2: Mogao Grottoes year-round atmospheric environment.

\subsection{Engineering Geology and Hydrogeological Conditions}

2.3.1. Engineering Geology Conditions. Dunhuang Mogao Grottoes are located at the western end of Hexi corridor, at the upper edge of alluvial-diluvial fan formed by the outlet of Daquan River. The plain in the front of Mogao Grottoes is class I terrace, and the class II terrace here has been eroded and destroyed, forming a steep cliff with a height of approximately $45 \mathrm{~m}$.

The extended length of grottoes is $\sim 1680 \mathrm{~m}$ and is positioned $10-45 \mathrm{~m}$ away from the floor of the cliff body, containing mainly existing statues and murals of all the dig remaining curves arranged in two to four layers, roughly north-south. The length of the south vertical cliff body is $920 \mathrm{~m}$ at about a slope of approximately $40^{\circ}$, and the height is $10-20 \mathrm{~m}$ in the upper part, presenting the characteristics of gentle up, steep down, and perpendicular to the horizontal plane. The height of the cliff body decreases gradually from south to north, in line with the topographic height along the direction of the river and finally ends up in the vast flat Gobi Desert in the north.

2.3.2. Rivers and Hydrogeological Conditions. Daquan River connects to Dongshuigou in the east and near the Dang River in the west, constituted by the surface and overflowing sub-

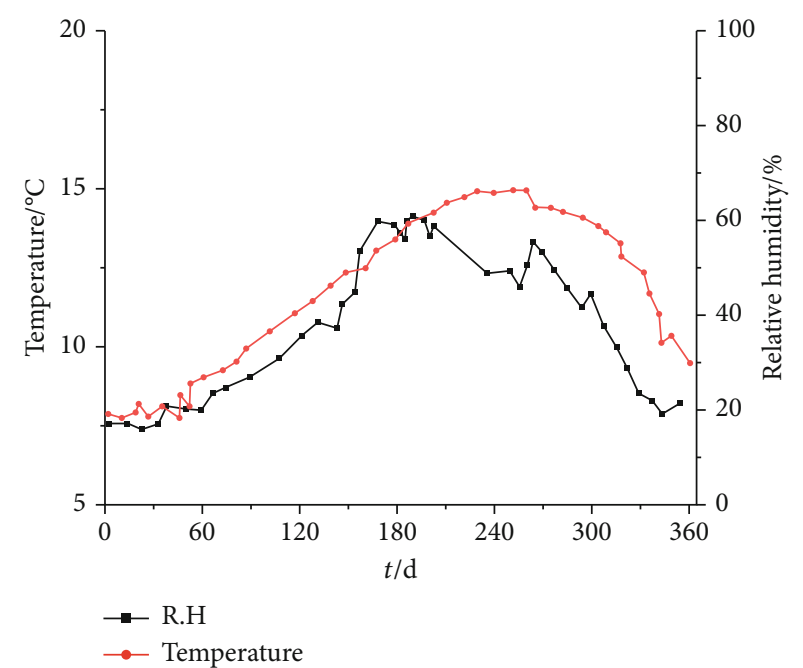

FIgURe 3: Annual environmental monitoring curve in hole 108.

surface water with only surface river in the Mogao Grottoes area of Dunhuang. The total drainage area is $1131.12 \mathrm{~km}^{2}$. The main ditch length was $71.19 \mathrm{~km}$ from Mustang Mountain in the south to Mogao Grottoes in the north. The Daquan River first passes through Sanwei Mountain, then flows through Mogao Grottoes, and joins Dang River, and finally flows into Shule River, belonging to the Shule River system. The average annual flow is $0.08 \mathrm{~m}^{3} / \mathrm{s}$ with short of flowing, except the annual flood season.

2.4. Characteristics of Temperature and Humidity Environment in the Cave. Based on the existing research progress, the variation law of temperature and humidity is summarized in the west surrounding rock mass of cave 108 in Dunhuang Mogao Grottoes (Figure 3). The analysis of the annual environmental monitoring curve showed that the external factors affected to a significantly high state, while the fluctuation was nonsignificant in Dunhuang Cave 108. The annual minimum temperature was $4.5^{\circ} \mathrm{C}$; the highest temperature of the cave was $15^{\circ} \mathrm{C}$; the time period of high temperature during 180-300 d with the hysteretic nature of the caves indicates that atmospheric humidity and humidity of caves are directly affected by precipitation in 150-210 d range; however, the annual climatic environment with cold in the summer and warm in the winter resulted in humidity below $80 \%$ of the whole humidity. The fluctuation in the temperature inside the caves was related to the annual atmospheric temperature.

The occurrence condition was continuously monitored during the drilling of the support body of murals, and the monitoring curve is shown in Figure 4.

Temperature more or less becomes constant with increasing depth, with the maximum fluctuation range from 7 to $15^{\circ} \mathrm{C}$. The overall trend of monitoring curve showed that the relative humidity increases with the depth of the surrounding rocks, and the annual fluctuation in humidity was not significant. The relative humidity was even more than $95 \%$ while sometimes was stable to $100 \%$ of the detection data, whereas the length exceeded $2.5 \mathrm{~m}$. This phenomenon 


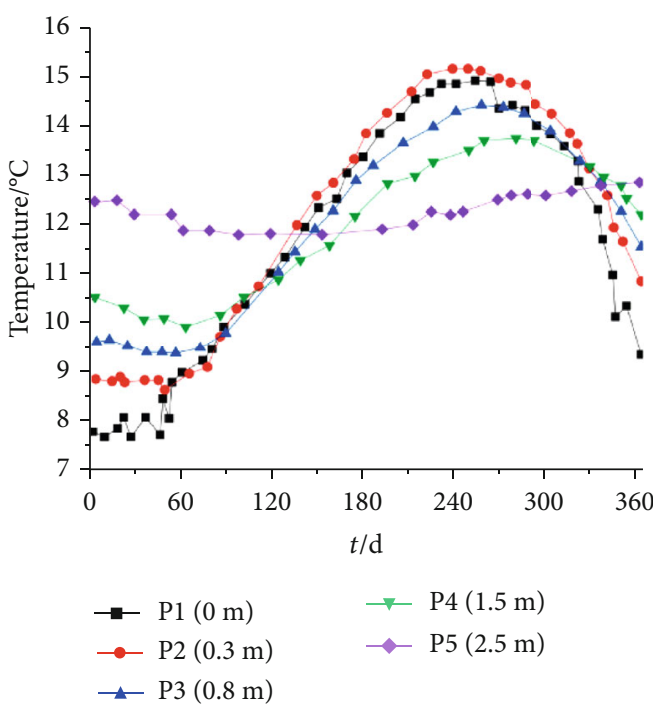

(a) Temperature

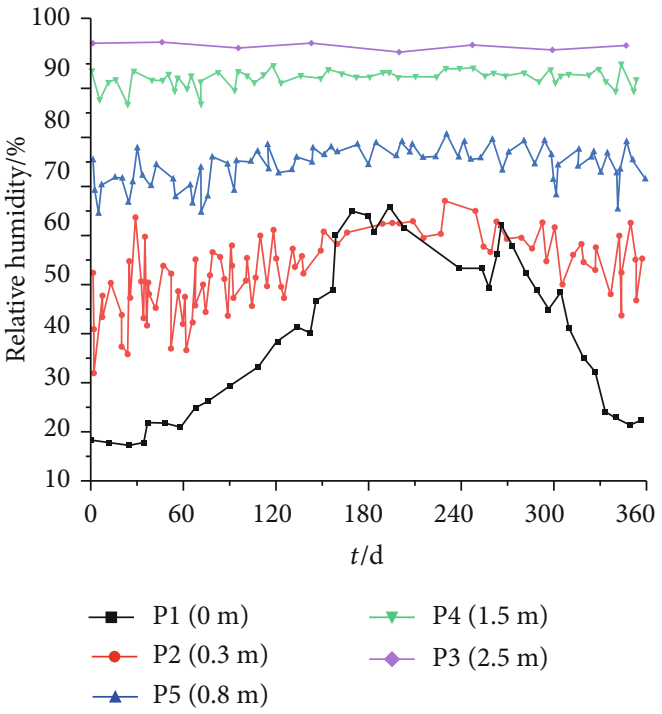

(b) Humidity

FIGURE 4: 108 environmental monitoring curve of occurrence in boreholes.

showed that in the deep support body, the water was completely in the gaseous condition, and the internal humidity remained higher throughout the whole year, and the relative humidity was $100 \%$ in the deep drilling area during drilling formatting. At a depth of $2.5 \mathrm{~m}$, the humidity level was always $100 \%$. With increasing depth, the relative humidity decreased, indicating the loss of water in the shallow support, and the balance distance was $2.5 \mathrm{~m}$.

\section{Intelligent Testing System for Soft Rock Hydrologic Liquid Water}

In order to study the water characteristics of the surrounding rock of Mogao Grottoes in Dunhuang, the intelligent testing system mainly comprising three parts main experiment box, weighing subsystem, and data acquisition subsystem of soft rock aqueous liquid water was developed by combining the absorption characteristics of the rock and water samples of Mogao Grottoes in Dunhuang.

3.1. Main Test Chamber. The main experimental chamber is a large box, placed in the main device of the water absorption experiment in the laboratory. Eight scales and eight rock samples (four nonpressurized rock samples and four pressurized rock samples) were kept in the studio interior space. The upper and middle parts of the studio are provided with a balance bracket, placed on the bracket, and the water supply bucket is at the top of the balance. A rock sample placement box, used to place rock samples, is also placed inside. The temperature and humidity test device recorded the temperature and humidity data, which were then transferred to the dashboard in the box at any time.

The specification of the system main experiment chamber was $1300 \mathrm{~mm}$ (length) $\times 1000 \mathrm{~mm}$ (width) $\times 1700 \mathrm{~mm}$ (height). The front of the box body has eight grooves (Figure 5), with a size of $150 \mathrm{~mm}$ (width) $\times 400 \mathrm{~mm}$ (height). The transverse distance of each other groove was $140 \mathrm{~mm}$.

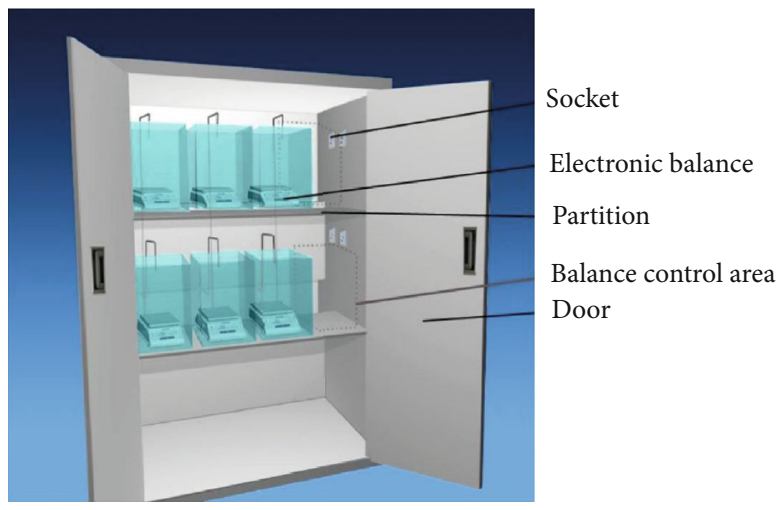

FIGURE 5: Front view.

The bottom of the upper groove was positioned $295 \mathrm{~mm}$ away from the lower groove, and the bottom distance between the lower groove and the box was $50 \mathrm{~mm}$. The temperature and humidity instrument panel was installed on the upper part of the cabinet, and their specific size was determined by the size of the instrument panel.

A rectangular hole with a specification of $85 \mathrm{~mm}$ ( transverse length) $\times 35 \mathrm{~mm}$ (vertical height) was arranged responsibly for importing power line and exporting serial port line in the lower part of the box body. The upper end of the hole positioned $750 \mathrm{~mm}$ away from the bracket on the balance, and the right side of the hole was $650 \mathrm{~mm}$ away from the back of the box.

The bracket for the balance was divided into two layers (Figure 6) and has a push-pull type design with a width of $500 \mathrm{~mm}$. The distance between the upper bracket and the bottom of the box was $1135 \mathrm{~mm}$, and the lower bracket positioned $580 \mathrm{~mm}$ away from the bottom of the box. The bracket correspondence with the box was related to the closed door at the back of the box. The bottom and top surfaces were 


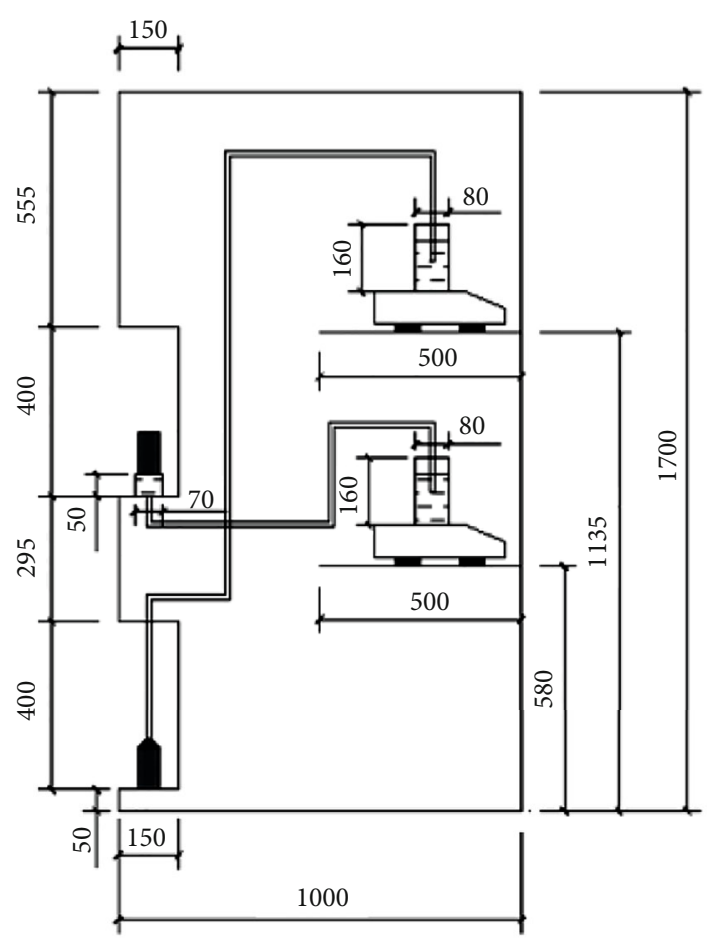

Figure 6: Later view.

supposed to reserve a hole with a diameter of $10 \mathrm{~mm}$ on the upper groove.

3.2. Weighing Subsystem. The weighing subsystem part is composed of eight electronic balances, placed on the platform of the upper and middle parts of the main experiment box and connected to the computer through the data line to realize the transmission of weighing data.

3.3. Data Acquisition Subsystem. The data acquisition subsystem consists of a computer in which a compiling program module was installed to instantly read and store rock weight change data transmitted by the electronic balance connected to it. The Intelligent Test System for Water Absorption of Deep Soft Rock is shown in Figure 7.

\section{Intelligent Testing System for Soft Rock Hydrological Gaseous Water}

4.1. Working Principle. Professor He Manchao of the China University of Mining and Technology (Beijing) put forward the fact that the great difference in the adsorption of various gases is due to different types of deep soft rocks in varying temperature and humidity environments.

4.2. System Composition and Function. The whole structure of the intelligent testing system of the soft rock hydrologic gaseous water comprised two boxes, as shown in Figure 8.

A box in intelligent testing system is responsible for setting the temperature and humidity, and various gases for mixing (referred to as the gas mixing chamber) were set by the system of the box; then, the mixed gas was used as the

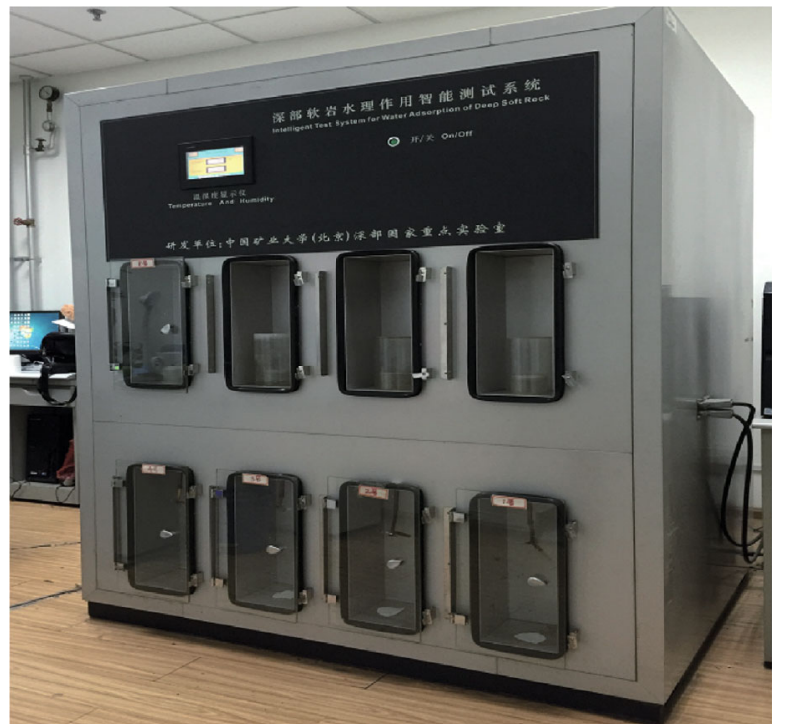

Figure 7: Intelligent test system for water absorption of soft rock.

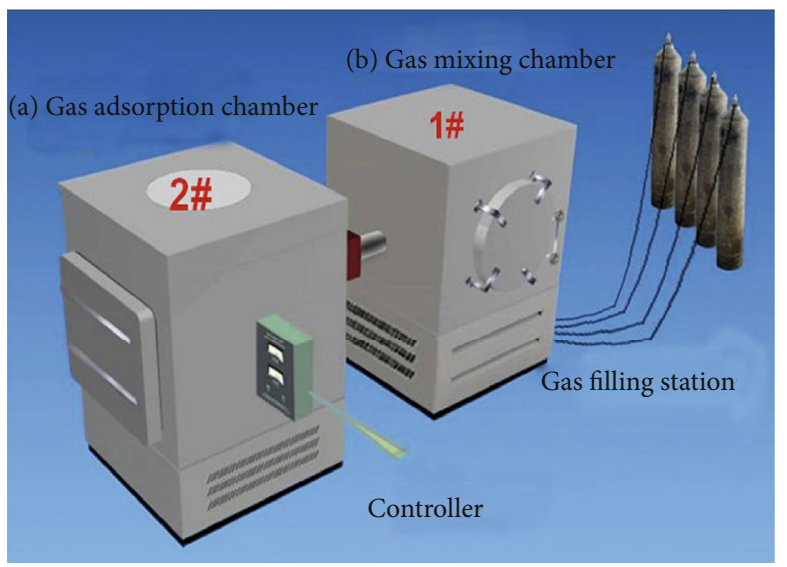

FIGURE 8: Soft rock gaseous water and water intelligent test system.

temperature input for temperature and humidity into the soft rock adsorption chamber (referred as the gas adsorption chamber) through the pipeline. The real-time data monitoring and curve collection were recorded using a controller through an external PC. When the temperature, humidity, and gas concentration in the last two boxes reach the set value, the valve of the gas conveying pipeline is closed, and the mixing chamber stops working; an adsorption experiment on the soft rock is carried out in the gas adsorption chamber in the box in the static state. The soft rock adsorption changes of the electronic balance in real time display on the computer were transmitted through the data, followed by recording them by suspending in the gas adsorption chamber with one end connected to the lower part of the weighing electronic balance.

The whole experimental equipment was divided into seven parts: temperature and humidity gas mixing chamber, soft rock gas adsorption chamber, gas source, electronic 

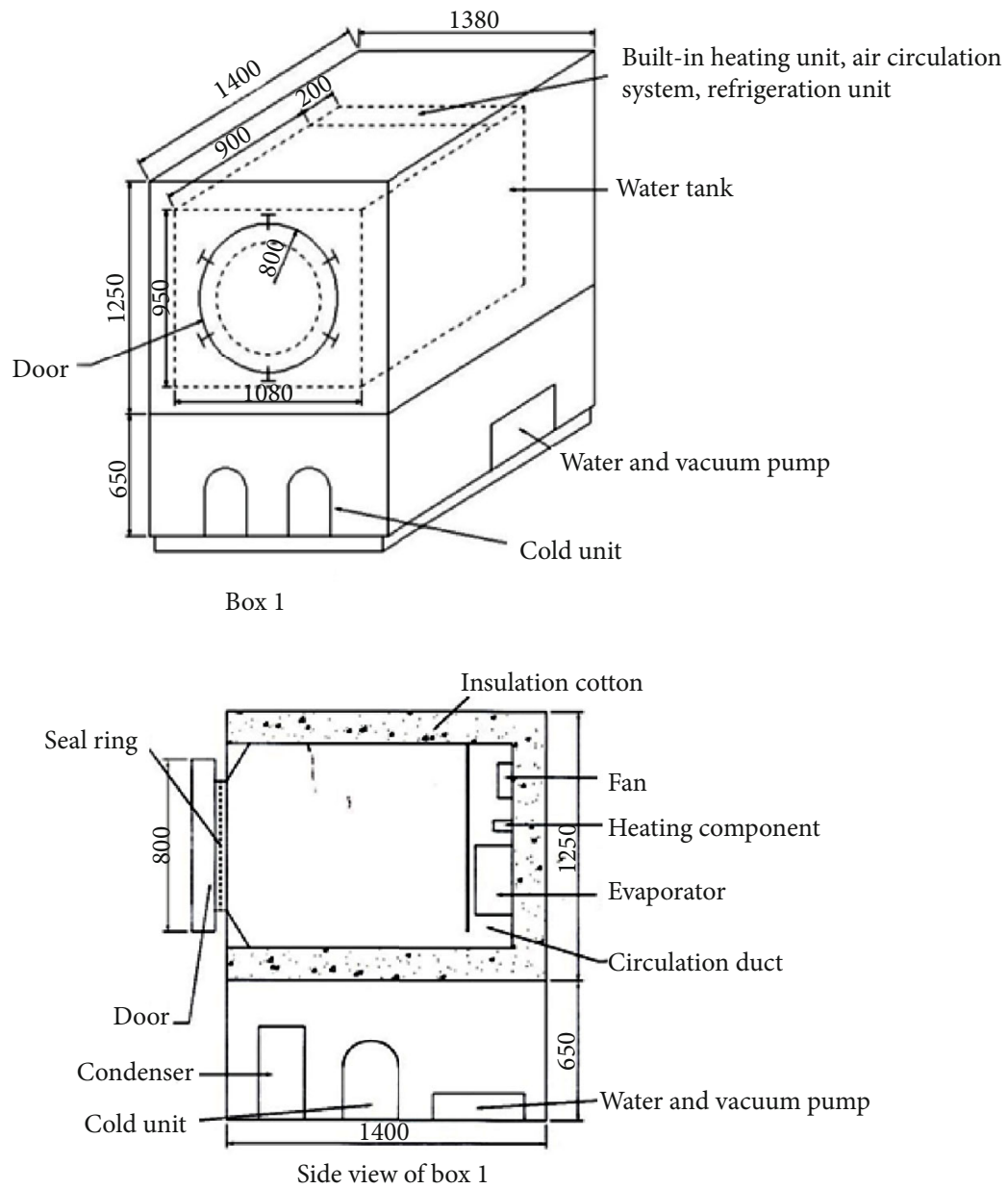

Figure 9: Schematic diagram of temperature and humidity gas mixing chamber design.

balance weighing, data acquisition system, control system, and safety protection device.

\subsubsection{Temperature and Humidity Gas Mixing Chamber (Box} No. 1). The temperature and humidity gas mixing chamber was made of SUS304 stainless steel material with inner carton following ST12 manufacturing process and surface electrostatic spraying divided into the upper and lower structure. The upper inner box comprised wind circulation structure, heating components, refrigeration components, temperature sensor, humidity sensor, and inlet for all types of gas and sensors; the lower layer of the cabinet mainly comprised a refrigeration system, vacuum compressor, humidifying water tank, and water pump; the back box was equipped with all types of gas intake solenoid valve and humidifier. The schematic design diagram of the temperature and humidity gas mixing chamber is shown in Figure 9.

The main functions of the No. 1 box were transporting the No. 2 box after the set temperature and humidity reached for four types of gases.

The operation process of the No. 1 box is as follows: (a) start the vacuum compressor to completely evacuate the air in the box (since vacuum pumping is easy to cause damage to the gas detection probe, it was upgraded to inject nitrogen to discharge the gas); (b) set the required temperature, humidity, and the concentration ratio of various gases on the touch screen of the control instrument for evacuating the air in the cabinet; (c) turn on the start button on the touch screen until the air in the box is evacuated; and (d) open the gas conveying solenoid valve, when all types of gases on the touch screen reach the preset value, and afterwards, the gas at required temperature and humidity is flown to the soft rock adsorption box through the gas conveyed pipeline. Forbid opening the solenoid valve on the gas conveying pipeline and turning out the whole equipment until the temperature and humidity of the gases in the two boxes reach the set value.

4.2.2. Soft Rock Gas Adsorption Chamber (Box 2 for Short). The structure of the soft rock gas adsorption chamber comprises upper, middle, and lower parts. The upper part is the area where the balance is placed, and the No. 2 main box is installed in the middle part, and the lower part has a frame. The material of the main No. 2 box is the same as that of the No. 1 box. The overall structure is divided into three layers: (a) the inner box, (b) the first insulation layer, and (c) the second insulation layer. The essential matter between the inner box and the first insulation layer is the air insulation layer with a thickness of $100 \mathrm{~mm}$ with heating components installed in it. In addition, the insulation of the inner box 


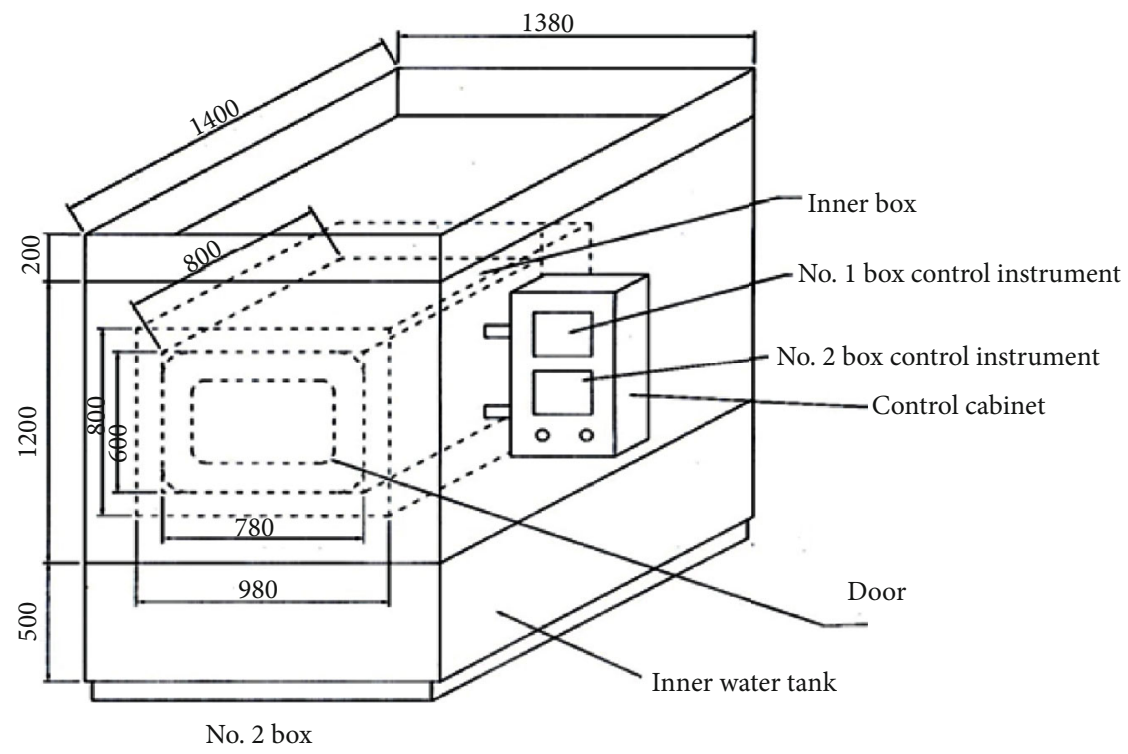

FIgURE 10: Design composition and principle of the soft rock gas adsorption chamber.

can realize different temperatures as the outer wall of the inner box is wrapped by cooling copper tubes. The temperature in the insulation layer will be consistent with that in the inner tank, while the box at a high temperature guarantees the longest test time. The heat preservation efficiency of the first air insulation is further strengthened as far as possible to keep up with the temperature of the set range result from the protection of the second insulation layer in the box, and the distance between them was $200 \mathrm{~mm}$. The top floor is bound to six pipes on the top of the inner box of the No. 2 chamber; moreover, six wires are connected to the bottom of six electronic weighing scales on the top through the pipe. The lower part of the No. 2 chamber is equipped with a liquid storage box and a small humidifier. The former is divided into two layers: (i) the inner layer stores antifreeze, used for the insulation of the inner box when the temperature is below zero, and (ii) the outer layer is insulated with a thickness of $150 \mathrm{~mm}$. When the temperature in the box is less than $1 \%$ of the set value during the experiment, the latter will automatically compensate the temperature to the set value. Furthermore, the gas solenoid valve will automatically open to compensate to the set value of the gas concentration, at which the gas enters the box through the bottom filter without affecting the specimen while the concentration of a certain gas in the box is less than $1 \%$ of the set value.

The main function of the No. 2 chamber is to provide an experimental environment to simulate the soft rock in order to maintain temperature, humidity, and various gases in a completely static state. The general working conditions of realizing its design function are as follows:

(1) Once the vacuum pump of the No. 2 box was turned on, the temperature reaches to the set value in the air insulation layer along with the No. 1 box; then, the gas is flown in the latter and is used as the input
(2) The front of the main chamber was equipped with two doors with linkage, one small inside and the other larger outside; the front of the former is connected to the back of the latter by a sliding rod

(3) Sealing ring installed between the connecting parts of the two doors and frames played a significant role in ensuring the sealing of the trunk. The leverage principle was used in the hydraulic cylinder to manipulate the gate of the outside result in preventing the leakage of the inside door and reinforcing the sealing and insulation of the chamber. In addition, the fluctuation of temperature in the No. 2 box was $\pm 1^{\circ} \mathrm{C}$, in a period of three days. The side view of the No. 2 box is shown in Figure 10

4.2.3. Gas Source Design. Air comprised four types of gases $\left(\mathrm{CO}_{2}, \mathrm{CH}_{4}, \mathrm{O}_{2}\right.$, and $\left.\mathrm{N}_{2}\right)$ and was filled in the cylinder connected to the gas mixing chamber through the trachea of the gas supply station for uniform temperature and humidity. Each gas line has a concentration sensor, and the input of the gas was controlled by an electromagnetic valve based on the experiments required for concentration with the fluctuation in the range $1 \%$ through the instrument set concentration ratio. The explosion-proof box placed was beneficial to the combustible and explosive gas.

4.2.4. Electronic Balance Weighing System. Six electronic weighing scales were put on the upper part of the No. 2 case, surrounded by $100 \mathrm{~mm}$ thick insulation layer, and three vacuum glasses of four layers with a diameter of $700 \mathrm{~mm}$ were embedded in the roof for a stainless steel flange. A closed, dry, and insulated environment was constructed to match up the base of the scales on the fixing style of the flange with a seal ring in order to prevent the top glass from moisture, affecting the stability of the weighing scales, and it was equipped with a heating 


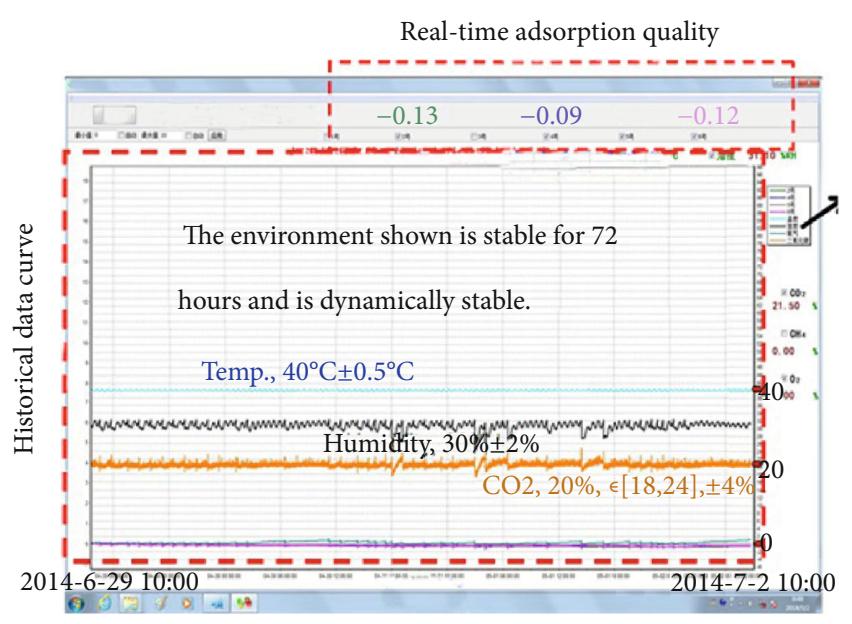

FIGURE 11: Computer terminal software interface.

resistance film on the glass and hold together with the desiccant making glass always in the dry state.

4.2.5. Data Acquisition System. The weight change of the soft rock was displayed using an electronic balance supposed for weighing the soft rock specimen in the adsorption chamber in real time. In the external computer terminal (PC), the control software written by the user was installed in advance and that software could simultaneously display the quality changes of multiple specimens in the experimental process in real time. In addition, the environmental parameters in the box such as temperature, humidity, and the concentration of different gases were also displayed in real time, as shown in Figure 11.

The soft rock was placed in the tray during the experiment, and the electronic balance immediately showed the weight, and thus, the accurate weight change of the soft rock in the adsorption room in time was determined. Each electronic balance had a data line, and the data line was connected to the computer. The data on each electronic balance was transmitted to the computer in real time to truly realize data transmission and storage.

During the data collection, the data cable socket of each balance was set in a sealed, moisture-proof, insulated, and shielded box, from which the data cable was extracted and connected to the computer.

4.3. Overall System Performance Test. In order to test the stability of the gaseous water intelligent testing system of soft rock hydrology, an integrated testing was carried out, in which its adsorption capacity was monitored under the specific environment of the soft rock by integrated testing.

The gray sandstone of a coal mine was selected as the debugging test specimen, and the rock samples were cylindrical, with standard samples of $50 \mathrm{~mm}$ in diameter and $100 \mathrm{~mm}$ in height, as shown in Figure 12.

The three specimens were put in the box, set at a temperature, relative humidity, and the $\mathrm{CO}_{2}$ content of $50^{\circ} \mathrm{C}, 80 \%$, and $20 \%$, respectively. The relationship between the experimental environmental parameters and the increase in the adsorption mass of the sample (Figure 13) was automatically

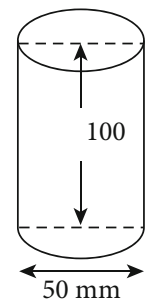

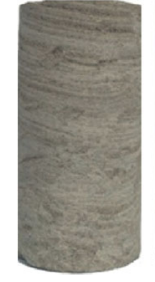

(a) $2 \#$

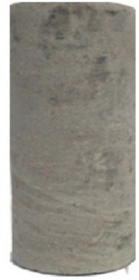

(b) $3 \#$

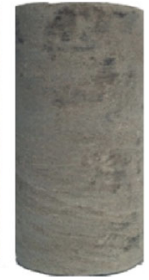

(c) $5 \#$
Figure 12: Gray sandstone samples from a coal mine in China.

recorded and drawn by the computer terminal software. The analysis indicates that the weight gain of the samples first showed a fast rising trend, and after a period of time, the weight gain of the samples gradually slowed down. Finally, the samples reached equilibrium or dynamic equilibrium. Based on the adsorption weight gain curves of the three samples, their adsorption masses were 1.7, 1.9, and 1.8 g. Subsequently, the relative humidity inside the box increased to $85 \%$ of the environment, because of the change in the environment due to the experiments. The relative humidity played a significant role in the Nos. 2 and 5 specimens, and their adsorption mass increased sharply. The adsorption mass of the No. 3 sample fluctuated obviously and showed an increasing trend.

The dynamic balance of multiple environmental indexes was achieved by the whole machine experiment process of up to $100 \mathrm{~h}$. At the same time, the experimental system monitored the adsorption mass curve of the specimen in the experimental box with increasing time. Relative humidity constant value floating exists in the process of experiment, causing obvious response of the specimen quality of adsorption. It shows that this experimental system could perform specific gaseous water adsorption. The hydrology simulation environmental parameters and the gaseous water adsorption response of the rock sample had a high sensitivity. In the near future, different rock and environment parameter combination for the soft rock under the condition of gaseous water adsorption characteristics should be analyzed.

\section{Experiment on Hydrological Action of Rock Samples in Dunhuang Grottoes under Multifield Coupling}

\subsection{Liquid Water Adsorption Characteristics of Rock Samples}

\subsubsection{Experimental Design}

(1) According to the field test data, the Mogao Grottoes are dry and lack rain in the dry season. However, a little water exists in the surrounding rock of the support body and is mainly transported in the support body by capillary action. A no-pressure water absorption experiment was carried out to simulate the change in the physical and mechanical properties of the rock body under capillary action. Three black sandstone samples from Mogao Grottoes were selected for the experiment to carry out nonpressure adsorption of liquid water under normal temperature and humidity 


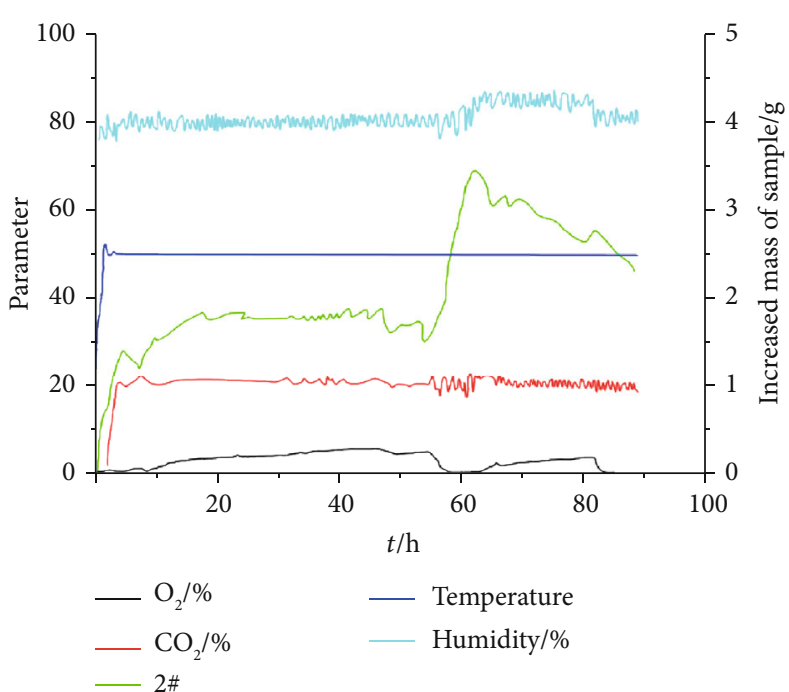

(a) 2\# weight gain curve of sample

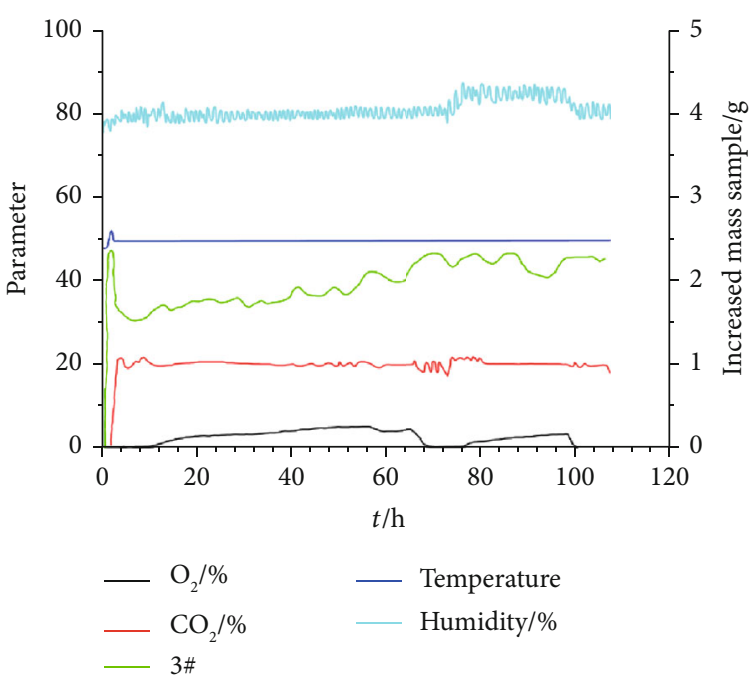

(b) Weight gain curve of sample No. 3

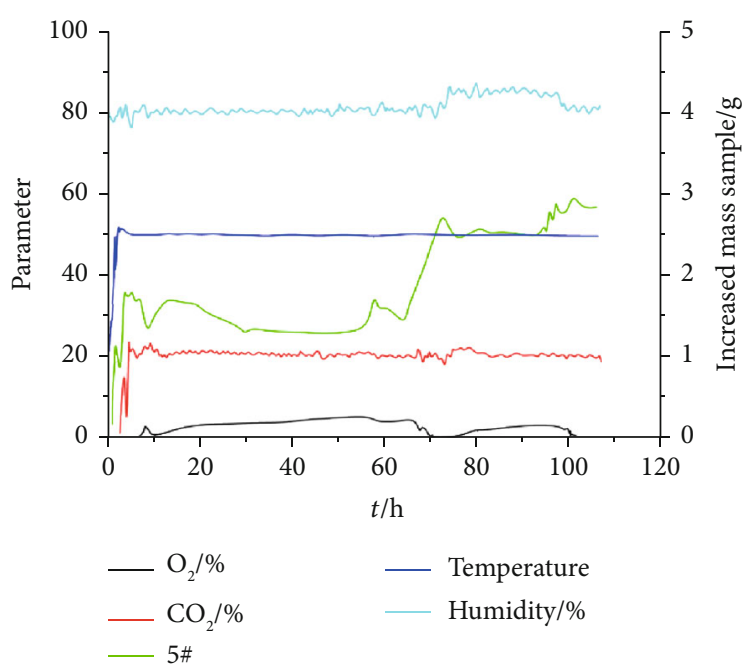

(c) Weight gain curve of sample No. 5

Figure 13: Experimental curve of the whole system.

to analyze the characteristics of liquid water adsorption of rock samples and factors affecting under the nonpressure water absorption conditions

(2) In the rainy season, the surrounding rocks of the support body of Mogao Grottoes were mainly affected by the atmospheric precipitation and garden pouring, and liquid water mainly influenced the surrounding rocks of the support body through osmosis. Four siltstone samples were selected to conduct the water absorption under pressure, which could simulate the regular change in physical and mechanical properties of rock mass caused by rainwater infiltration. The characteristics of liquid water adsorption of rock samples and factors affecting under pressure water absorption were analyzed

The nonpressure and pressure water absorptions of three black sandstone samples named as HSY-1 to HSY-3 and FS1 to FS4 were investigated. The data collected using the balance and sensor were transmitted to the Microsoft Access database through the data transmission system, and then, the original data were exported and processed from the Microsoft and Access databases. After that, the water absorption characteristic curve of the black sandstone samples was obtained, and the correlation analysis was carried out based on the curve.

5.1.2. Analysis of the Characteristics of Black Sandstone Water Absorption without Pressure. According to the experimental data of black sandstone samples, the statistical data of the water absorption of the rock samples was arranged, as listed in Table 1.

(1) The Black Sandstone Q-t Diagram. The relationship between the water absorption $(Q)$ and time $(t)$ of the selected black sandstone samples HSY-1, HSY-2, and HSY-3 in the Mogao Grottoes of Dunhuang is shown in Figure 14. 
TABLE 1: Statistical table of water absorption characteristics of the black sandstone.

\begin{tabular}{lccccc}
\hline Lithology & Numbering & Pretest quality/g & Water quantity/g & Water saturation absorption/\% & Sample description \\
\hline \multirow{3}{*}{ Black sandstone } & HSY-1 & 172.04 & 82.47 & 47.93 & Gray black, short texture, a large \\
& HSY-2 & 192.87 & 93.74 & 48.60 & amount of amorphous material \\
& HSY-3 & 189.19 & 89.95 & 47.54 & \\
\hline
\end{tabular}

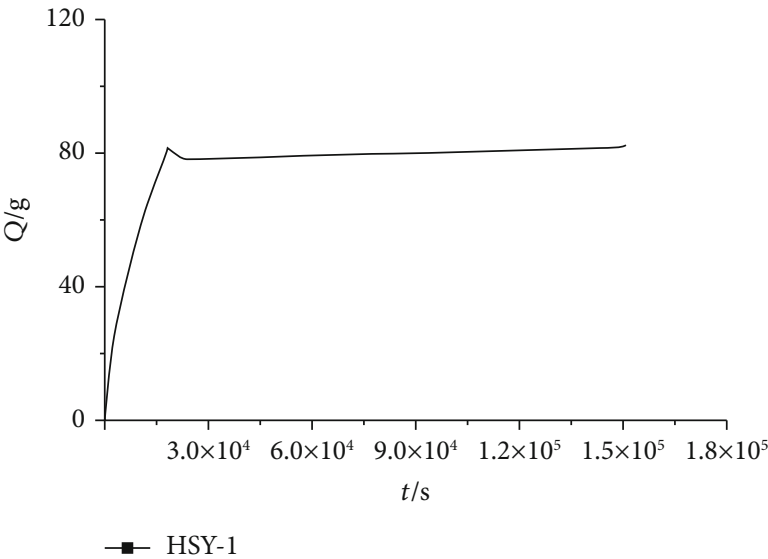

(a) HSY-1

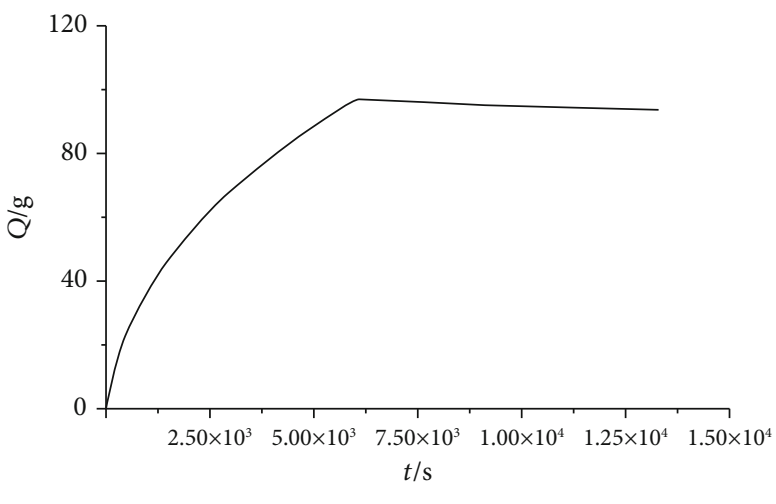

HSY-2

(b) HSY-2

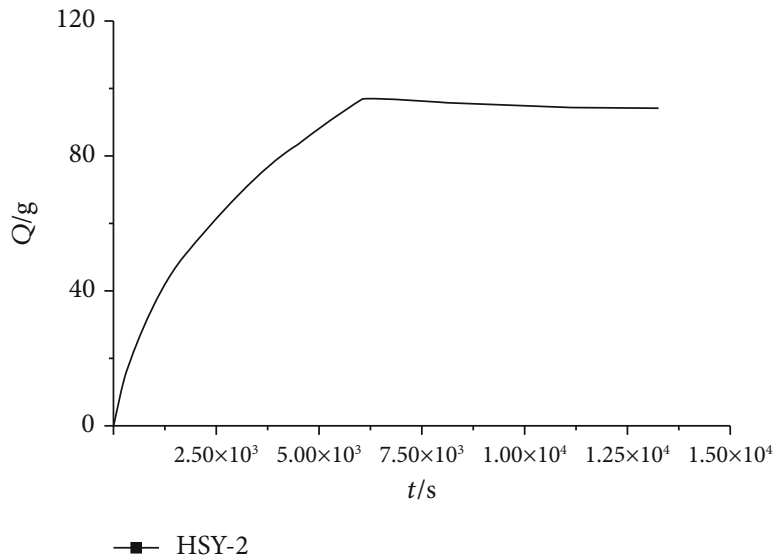

(c) HSY-3

FIGURE 14: Black sandstone Q- $t$ curve of water absorption nonpressure.

According to the water absorption experimental data, the water absorption curve $(Q-t)$ was drawn with time $t$ as the abscissa and water absorption $Q$ as the ordinate. The $Q-t$ curve of water absorption characteristics showed basically the same water absorption trend for the three black sandstone samples. At the beginning of the experiment, the curve showed a steep trend, and the water absorption increased rapidly until it reached saturation and then became stable. The final water absorption capacity of the black sandstone samples 1,2, and 3 in the saturated state was relatively similar, 82.47, 93.74, and $89.95 \mathrm{~g}$, respectively. The average water absorption capacity of the three black sandstone samples was $88.72 \mathrm{~g}$, and the time required to reach saturation was 20000,5000 , and $10000 \mathrm{~s}$, respectively, and was significantly different.
(2) $w$-t Diagram of Black Sandstone Samples. Figure 15 shows the relationship between the water absorption rate $(w)$ and time $(t)$ of the selected black sandstone samples HSY-1, HSY-2, and HSY-3 in Mogao Grottoes.

According to the water absorption experimental data, the water absorption curve $(w-t)$ was drawn with the water absorption time $t$ as the abscissa and the water absorption rate as the ordinate. According to the water absorption characteristics $(w-t)$ curve, the bibulous rate of the three black sandstone samples over time showed the same change trend. Initially, the water absorption experiment curves were steep, and the bibulous rate was relatively large. With increasing time, the trend gradually slowed down until reaching to a saturation point, and then, it became close to zero, indicating 


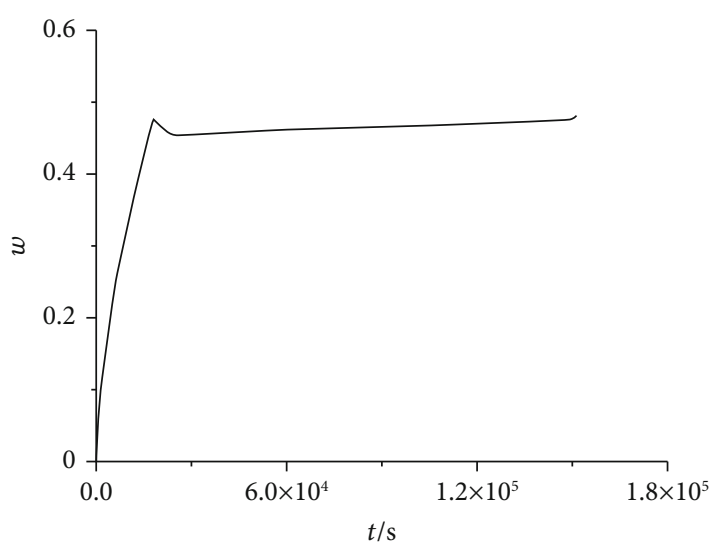

HSY-1

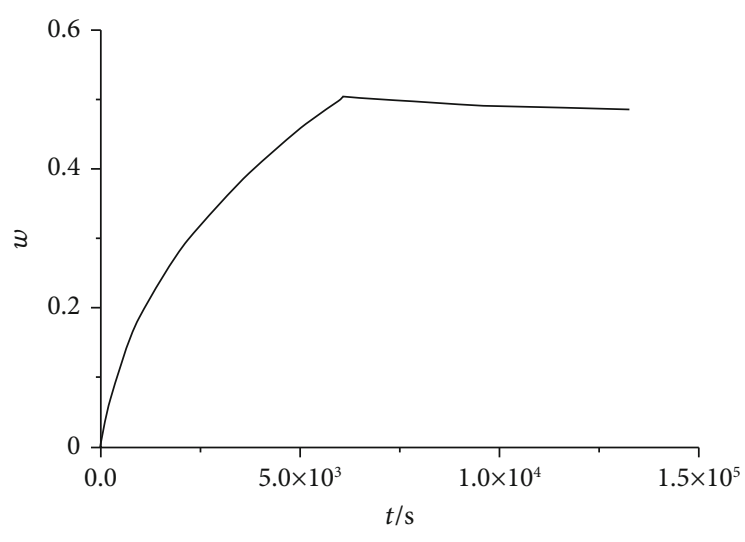

HSY-2

(a) HSY-1

(b) HSY-2

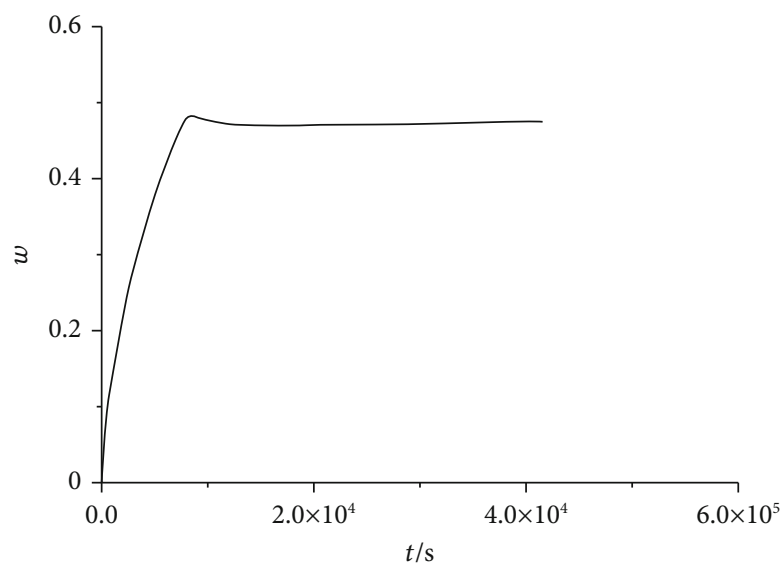

HSY-3

(c) HSY-3

FIGURE 15: Black sandstone $w$-t curve of water absorption nonpressure.

that the water absorption of the samples at this time was close to the saturated steady state. The saturated water absorption rates of the black sandstone sample Nos. 1, 2, and 3 are relatively similar and were $47.93 \%, 48.60 \%$, and $47.54 \%$, respectively, and the average water absorption rate was $48.02 \%$, with strong water absorption ability.

(3) Comparison of Nos. 1-3 Black Sandstone Samples. The difference in the water absorbing capacity and saturated water absorption was due to the nuances among the selection of the size and weight of the three black sandstone samples; therefore, not only water quantity of each sample and saturated water absorption should be analyzed but also the experimental results of the three samples showing the lithology trend of water absorption, and water absorption characteristics should be investigated in detail.

Based on the experimental data, the water absorption time $(t)$ was taken as the abscissa and the water absorption rate $(w)$ as the ordinate. The experimental data of HSY-1, HSY-2, and HSY-3 were plotted on the same coordinate axis to obtain the comparison graph of the water absorption curve $(w-t)$. The logarithm of the ordinate $(w)$ was taken to obtain the $(\ln w-t)$ single logarithm curve. The logarithm was taken for both abscissa $(t)$ and ordinate $(w)$ to obtain $(\ln w-\ln t)$ double logarithmic curve, as shown in Figure 16.

It was found that in the early stage of the experiment, the water absorption capacity of the three samples was relatively strong. With increasing time, the water absorption rate decreases until the samples are saturated. In the end, the saturated water absorption rate of the three samples was steady at about approximately $48 \%$, and the $w-t$ curve, $\ln w-t$ curve, and $\ln w-\ln t$ curve of the three samples were all convex, and the trend of the water absorption curve was consistent.

5.1.3. Analysis of Pressure Water Absorption Characteristics of Siltstone. Four samples numbered from FS1 to FS4 were selected for pressurized water-absorbing experiments, as shown in Figure 17 and the basic parameters of the sample with pressure absorbing siltstone in Table 2. 


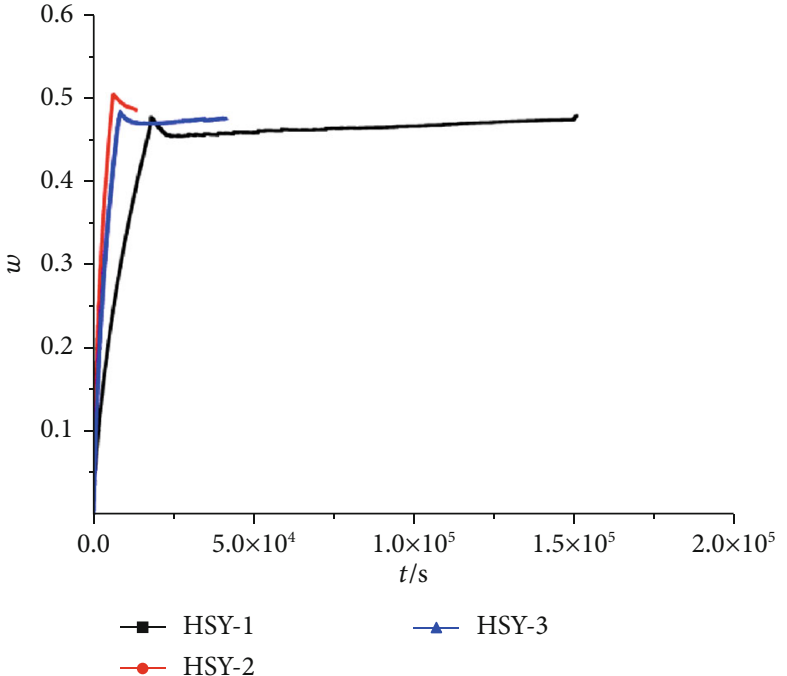

(a) $w-t$ curve contrast

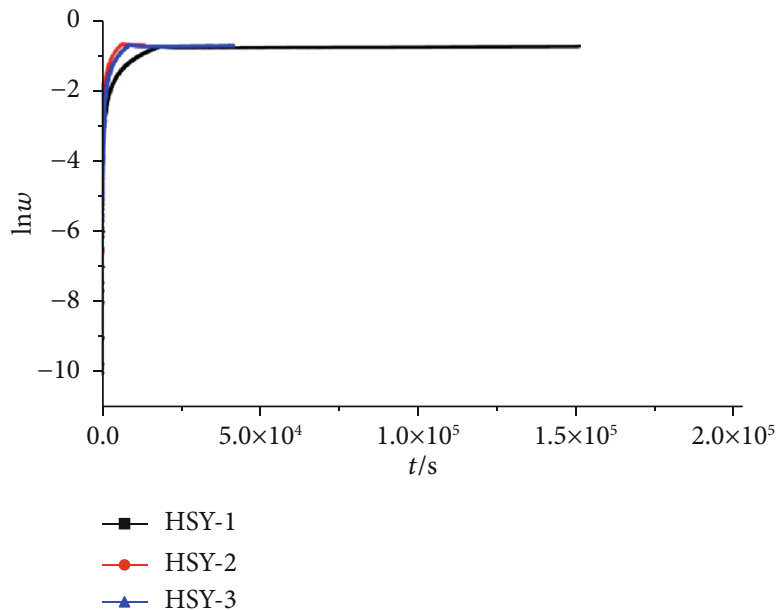

(b) $\ln w-t$ curve contrast

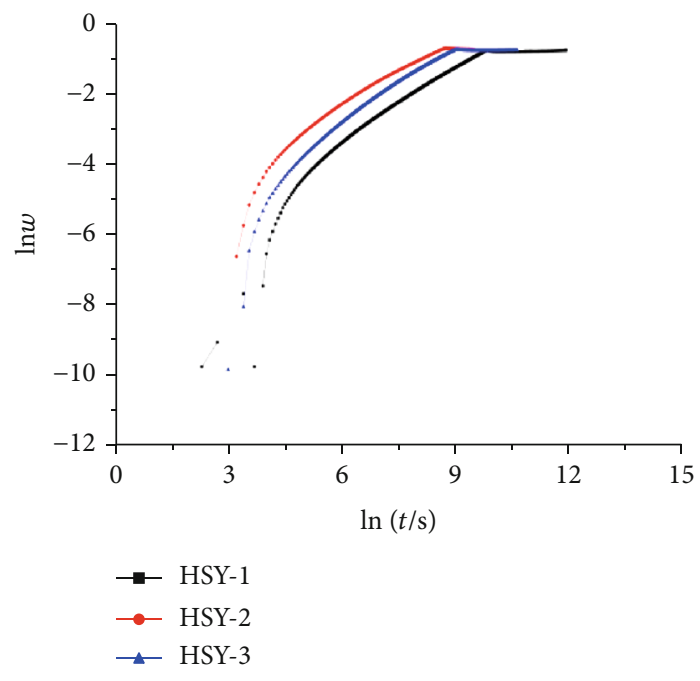

(c) $\ln w-\ln t$ curve contrast

FIGURE 16: Correlation curves of black sandstone samples.
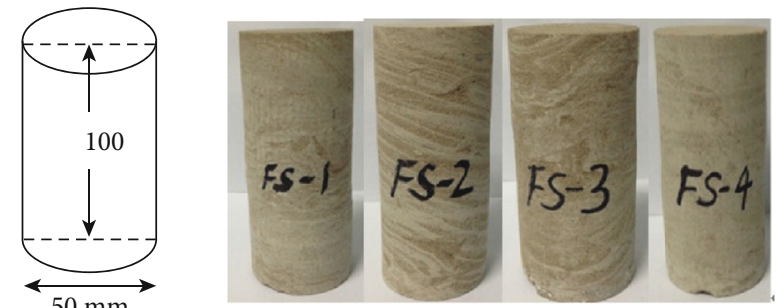

Figure 17: Pressure absorbent siltstone specimens.

(1) Water Absorption by the Siltstone Samples under Pressure by the Q-t Diagram. The relationship between the water absorption $(Q)$ and time $(t)$ of siltstone samples FS1-FS4 selected from Mogao Grottoes was obtained by plotting
TABLE 2: Basic parameters of pressure-absorbing siltstone specimens.

\begin{tabular}{ccccc}
\hline Lithology & Numbering & Diameter/mm & Height/mm & $\begin{array}{c}\text { Natural } \\
\text { quality/g }\end{array}$ \\
\hline \multirow{4}{*}{ Siltstone } & FS1 & 49.61 & 76.52 & 484.77 \\
& FS2 & 49.58 & 109.68 & 470.57 \\
& FS3 & 49.51 & 109.19 & 400.76 \\
& FS4 & 48.82 & 100.50 & 430.09 \\
\hline
\end{tabular}

the time of water absorption as the abscissa and the amount of water absorption as the ordinate from the experimental data of water absorption under pressure, as shown in Figure 18. 


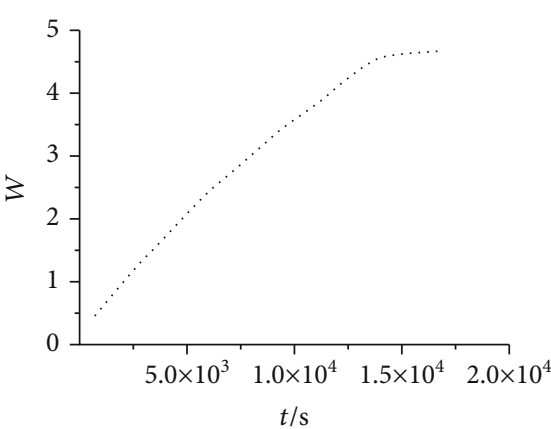

- FS1

(a) FS1

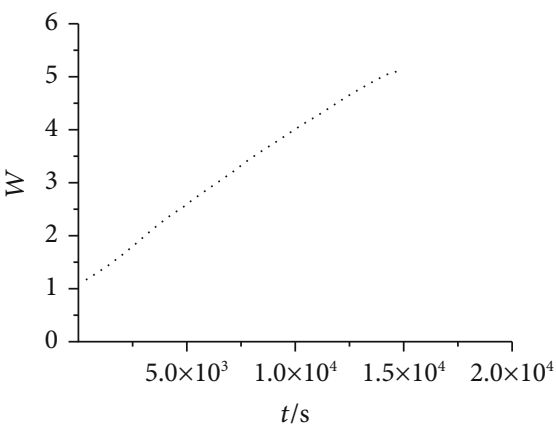

- FS3

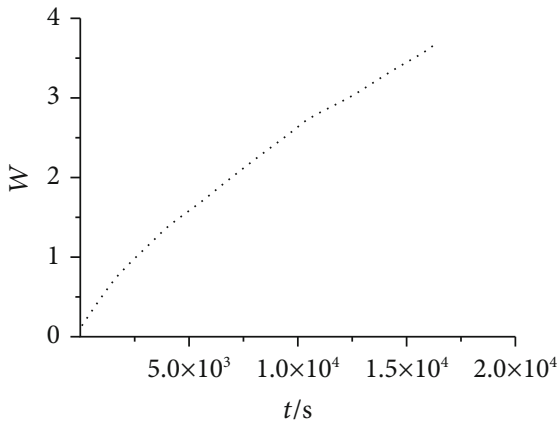

- FS2

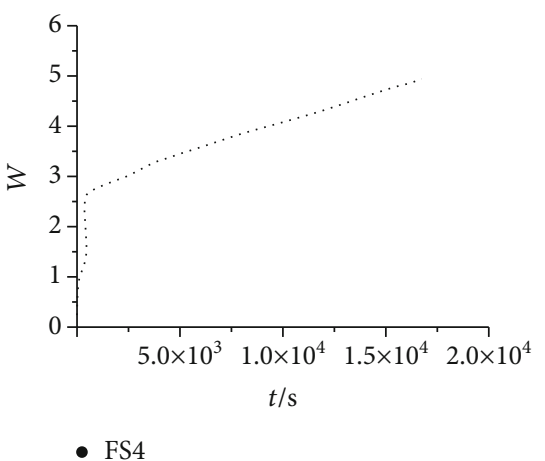

(d) FS4

(c) FS3

FIGURE 18: Pressure water absorption $Q-t$ curve of the siltstone samples.

The water absorption of the four siltstone samples from the water absorption characteristic $Q-t$ curve showed a consistent tendency. The initial water absorption curve was steeper, as the water absorption increased rapidly.

(2) Water Absorption of Siltstone Sample under Pressure with the $w$-t Diagram. The relationship between the water absorption rate $(w)$ and time $(t)$ of samples FS1-FS4 from the Mogao Grotto siltstone was established in Figure 19. According to the experimental data of water absorption rate in the siltstone samples, the water absorption process $(w-t)$ curve was obtained by plotting water absorption time $(t)$ as the abscissa and water absorption rate $(w)$ as the ordinate.

The water absorption rate of the three rock samples had basically the same trend with time. In the initial stage of the experiment, the curve had a steep trend, and the water absorption rate was large. With increasing time, the water absorption rate decreased slowly.

(3) Comparison of the Siltstone Sample Nos. FS1-4. Based on the experimental data, the water absorption time $(t)$ was taken as the abscissa and the water absorption rate $(w)$ as the ordinate. The experimental data of samples FS1, FS2, FS3, and FS4 were plotted on the same coordinate axis to obtain the comparison graph of the water absorption curve $(w-t)$. The logarithm of the ordinate $(w)$ was taken to obtain the $(\ln w-t)$ single logarithm curve. The logarithm was taken for both abscissa $(t)$ and ordinate $(w)$ to obtain the $(\ln w-\ln t)$ double logarithmic curve, as shown in Figure 20.

The comparative analysis of the four siltstone samples indicates that the water absorption rate of the four samples was relatively fast at the initial stage of the test. With increase time, the water absorption rate decreased until the samples were saturated, and the water absorption rate no longer increased with time. The $w-t$ curve and the $\ln w-t$ curve of the sample were convex, whereas the $\ln w-\ln t$ curve was concave.

\subsection{Softening Test of Water Absorption Strength of Rock Sample}

5.2.1. The Experimental Design. The particle morphology, cementation mode, and pore structure, namely, the chemical and microscopic physical properties of the rock mass, changed after absorbing water. As a result, the macroscopic mechanical properties of the rock mass changed, decreasing the rock strength. In a humid environment, the longer the rock body was exposed, the more water absorption occurred, the larger the water absorption range 


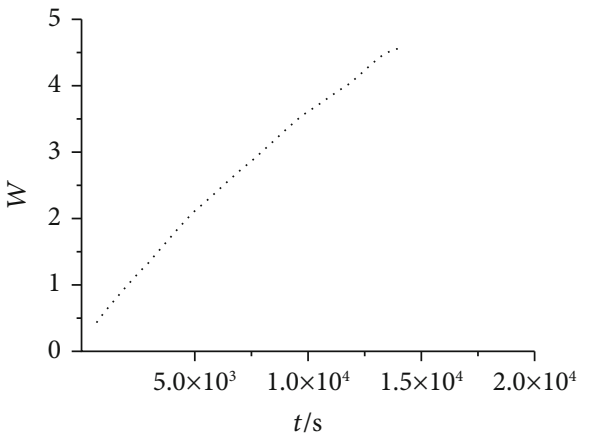

- FS1

(a) FS1

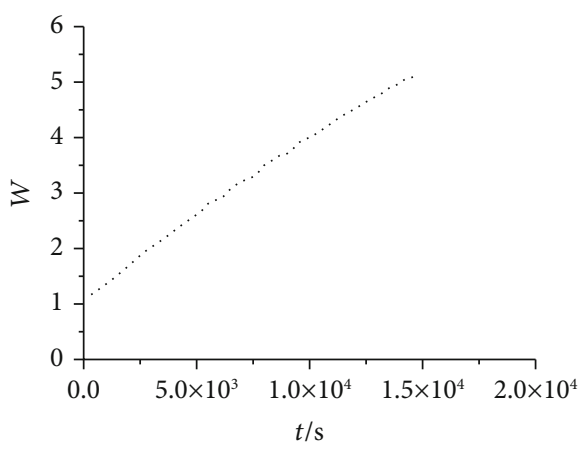

- FS3

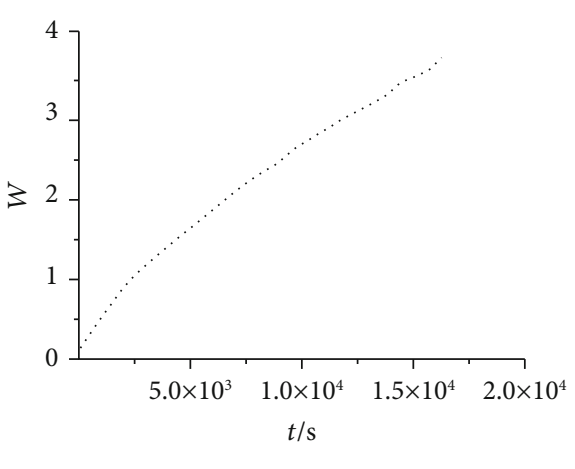

- FS2

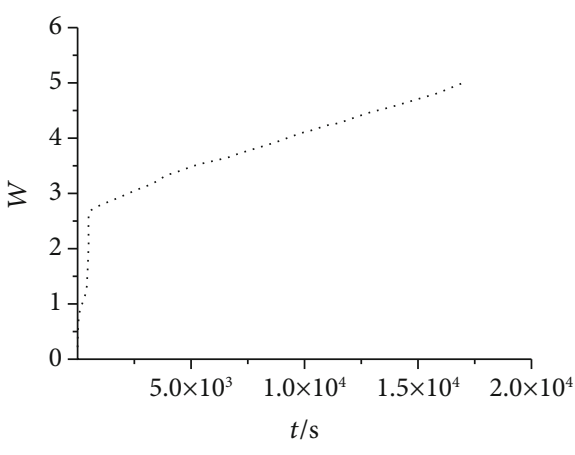

- FS4

(c) FS3

(d) FS4

Figure 19: Pressure water absorption $w$ - $t$ curve of the siltstone sample.

was, and the more severe the rock mass strength attenuation was. The relationship between the strength softening and water absorption time of the rock mass, i.e., the strength degradation function, is as follows:

$$
\sigma_{t}=f(t)
$$

where $\sigma t$ refers to the uniaxial compressive strength of rock after water absorption and $t$ is the water absorption time.

5.2.2. Experimental Methods and Procedures. In this experiment, uniaxial compressive tests were carried out on dry rock samples after water absorption at different times. The water absorption of each sample was recorded for a predetermined time. The sample was removed, and its surface water was wiped off, and its mass after the water absorption was accurately measured to reveal the final water absorption of the sample. Then, uniaxial compression test was conducted for the sample.

The formula for calculating the uniaxial compressive strength of rock:

$$
\sigma_{t}=P / A,
$$

where $\sigma t$ refers to the uniaxial compressive strength, MPa; $P$ refers to the failure load, $N$; and $A$ refers to the area of the specimens, $\mathrm{mm}^{2}$.

A total of seven siltstone samples numbered FS0, FS5, FS6, and FS7-FS10 were used. The photographs of the rock samples before the experiment are shown in Figure 21.

\subsubsection{Experimental Results and Analysis}

(1) Experimental Results and Analysis of Water Absorption Characteristics of Samples. The water absorption curves of samples FS5-FS6 and FS7-FS10 are shown in Figure 22, and the water absorption rate curve is shown in Figure 23.

The stress-strain curve of the uniaxial compression experiment under different water absorption rates of the siltstone samples is shown in Figure 24.

Sample strength test data are listed in Table 3.

The relationship between the compressive strength and water absorption of rock samples is shown in Figure 25.

The relationship between the elastic modulus and the water absorption of the rock sample is shown in Figure 26. 


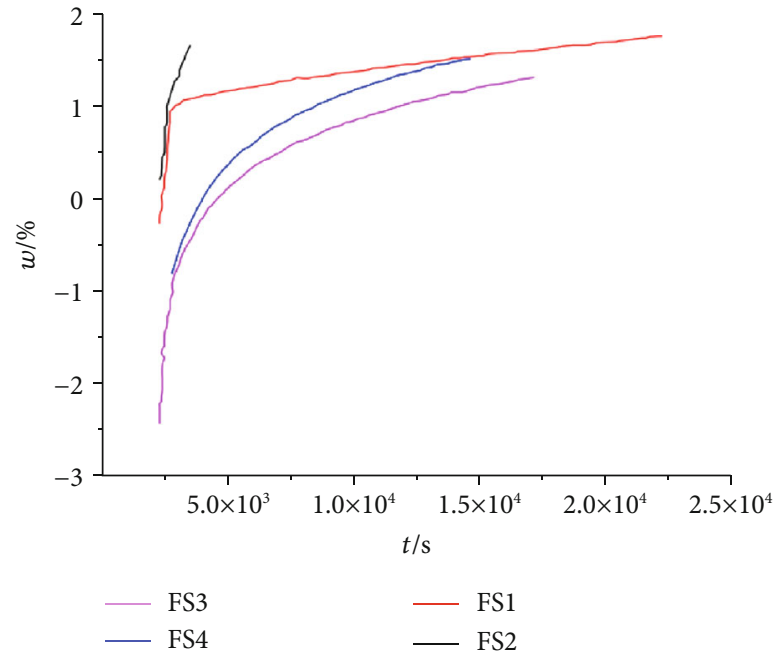

(a) $w-t$ curve contrast

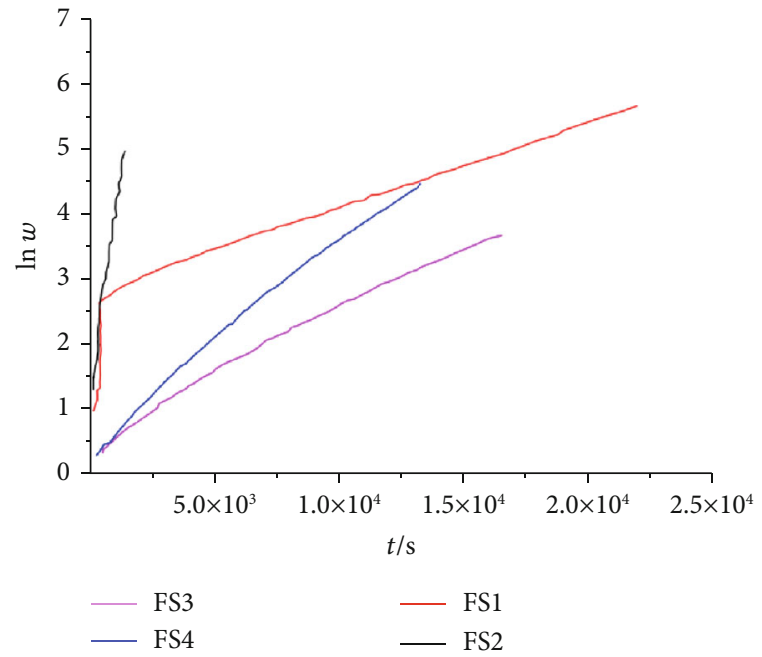

(b) $\ln w-t$ curve contrast

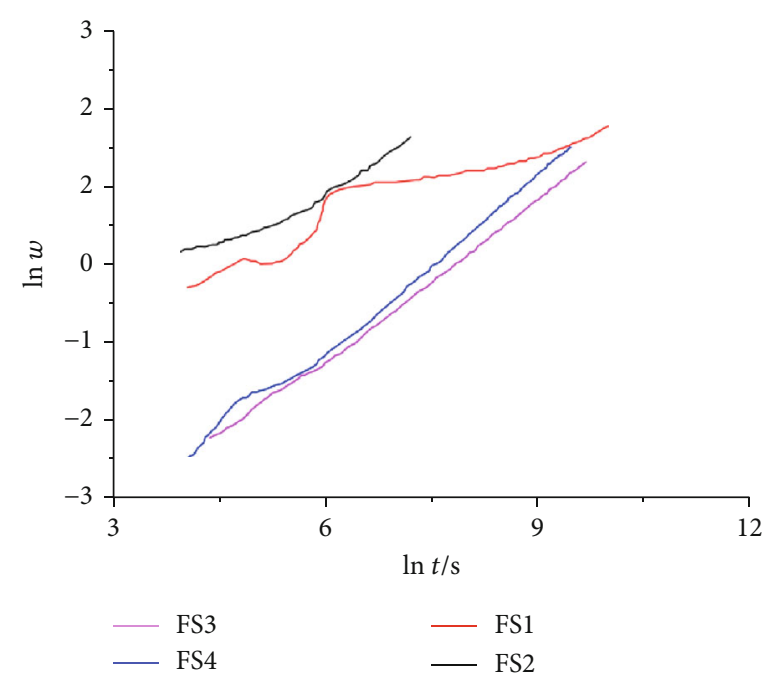

(c) $\ln w-\ln t$ curve contrast

FIGURE 20: Siltstone has pressure water absorption correlation curve.
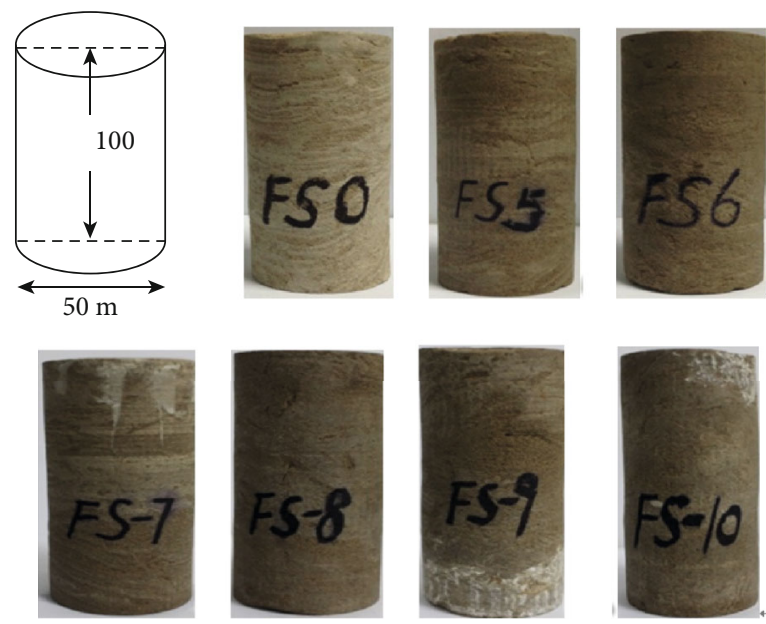

FIGURE 21: Strength softening test siltstone sample. 


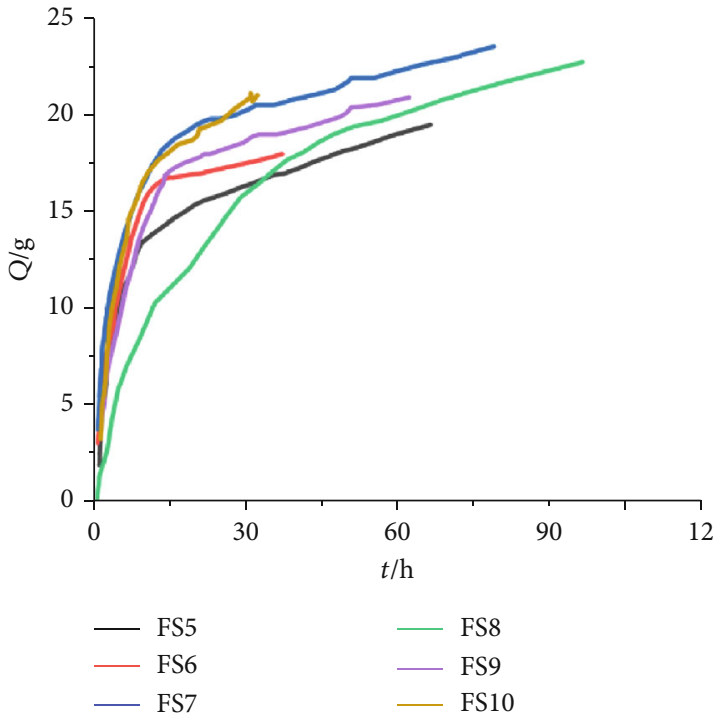

Figure 22: Curve of water absorption quantity of the siltstone samples.

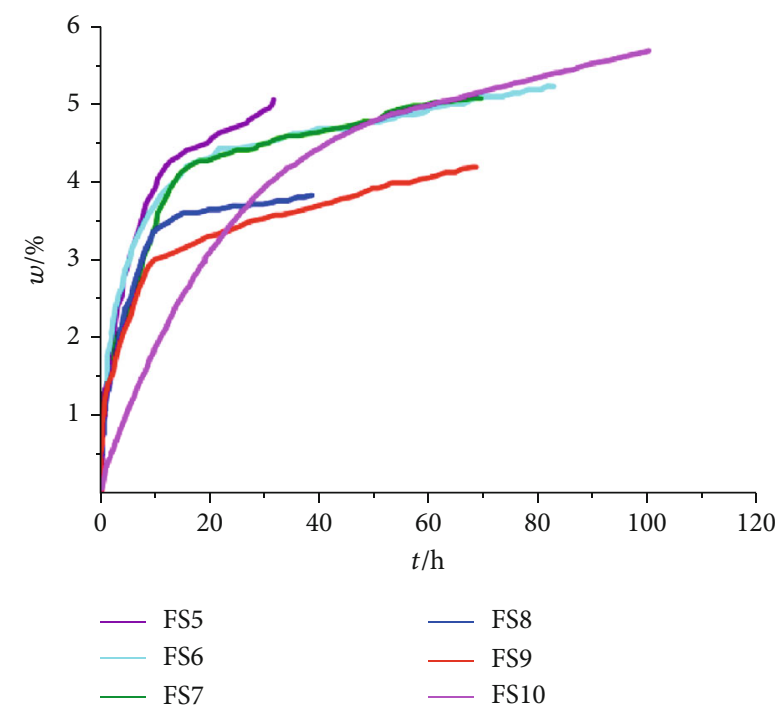

FIGURE 23: Curve of water absorption rate of the siltstone samples.

Figure 25 shows that the compressive strength of the rock sample decreases with increasing water absorption. Figure 26 shows that the elastic modulus of the rock sample is also inversely proportional to the water absorption rate, and the strength softening of the rock sample is closely related to the water absorption rate.

\subsection{Gas-Water Adsorption Experiment in Constant Temperature and Humidity Environment}

5.3.1. Experimental Design. In order to study the influence of the surrounding rock of the Mogao Grottoes in Dunhuang, Gansu, on the adsorption characteristics of gaseous water during the seasonal changes, two samples of mudstone and siltstone in Mogao Grottoes were selected from

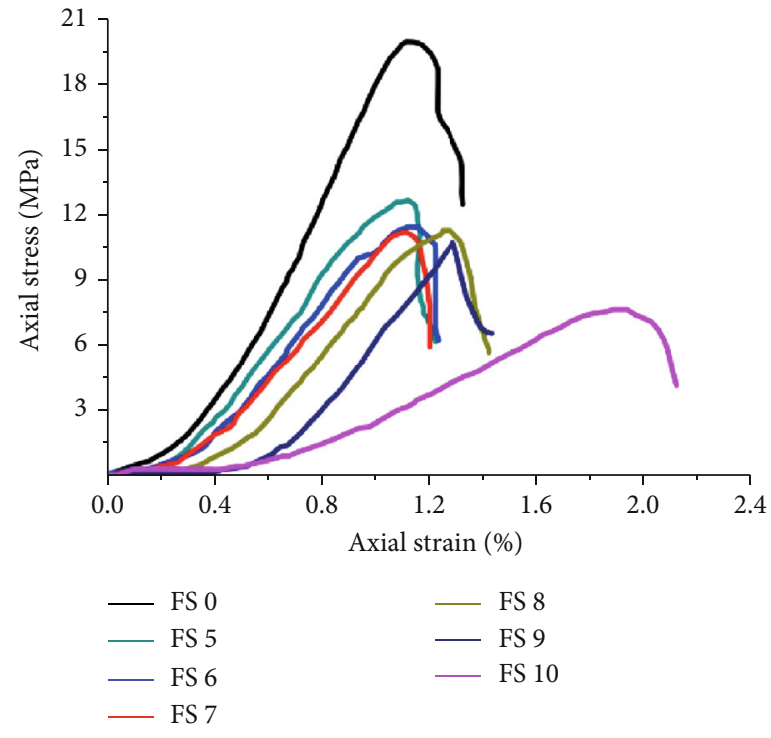

Figure 24: Uniaxial compression stress-strain curves of the siltstone samples at different water absorption.

the Suoyang City and Ta'er Temple. A total of 24 specimens were tested including soil and pagoda adobe samples. During the on-site environmental investigation, the climate characteristics of the Dunhuang area were as follows: rainy in the summer, large fluctuations of temperature, and low overall environmental humidity in the spring and autumn; in the winter, the ambient temperature was below zero, and the humidity was high. Based on the environmental monitoring data in the caves of Dunhuang Mogao Grottoes and the environmental parameters of the inner support of the borehole (surrounding rock), the environmental parameter settings of the gaseous water adsorption experiment are summarized, as listed in Table 4.

The simulation experiment of the support and surrounding rock and the rock sample of the Mogao Grottoes in the summer and winter was carried out.

\subsubsection{Experimental Results and Analysis}

(1) Experiments on the Adsorption of Aqueous Gaseous Water in the Mudstone Samples Selected Mogao Grottoes in the Summer. A total of eight mudstone samples from Dunhuang Mogao Grottoes were selected for in situ hydrological gaseous water adsorption experiment. According to the field number, four specimens were determined to be a group for testing. The first group of four specimens was numbered as 6-2, 8-2, N9-2, and N23-1; the second group of four specimens are numbered as follows: N1, N3-1, N6-1, and N17-1. The basic parameters of the specimens are shown in Table 5.

The first set of simulation was set up at an environment temperature of $30^{\circ} \mathrm{C}$ and a relative humidity of 95\%. The equilibrium curve of the experimental environment parameters is shown in Figure 27. After entering 
TABLE 3: Test results of strength softening of siltstone.

\begin{tabular}{|c|c|c|c|c|c|c|}
\hline Sample name & $\begin{array}{c}\text { Drying } \\
\text { quality (g) }\end{array}$ & $\begin{array}{c}\text { Water absorption } \\
\text { time }(t)(\mathrm{h})\end{array}$ & $\begin{array}{l}\text { Water quantity } \\
\text { (Q) (g) }\end{array}$ & $\begin{array}{l}\text { Bibulous } \\
\text { rate }(\%)\end{array}$ & $\begin{array}{c}\text { Uniaxial compressive } \\
\text { strength }(\mathrm{MPa})\end{array}$ & $\begin{array}{c}\text { Elastic modulus } \\
(\mathrm{GPa})\end{array}$ \\
\hline FS0 & 436.68 & 0 & 0 & 0 & 19.92 & 2.66 \\
\hline FS5 & 450.38 & 69.08 & 19.06 & 4.23 & 11.31 & 1.2 \\
\hline FS6 & 456.68 & 38.89 & 17.66 & 3.87 & 11.52 & 1.55 \\
\hline FS7 & 433.79 & 82.18 & 22.99 & 5.30 & 12.81 & 1.76 \\
\hline FS8 & 389.68 & 100.24 & 22.19 & 5.70 & 7.75 & 0.71 \\
\hline FS9 & 401.51 & 64.82 & 20.48 & 5.10 & 11.45 & 1.53 \\
\hline FS10 & 404.88 & 33.43 & 20.54 & 5.07 & 10.92 & 1.7 \\
\hline
\end{tabular}

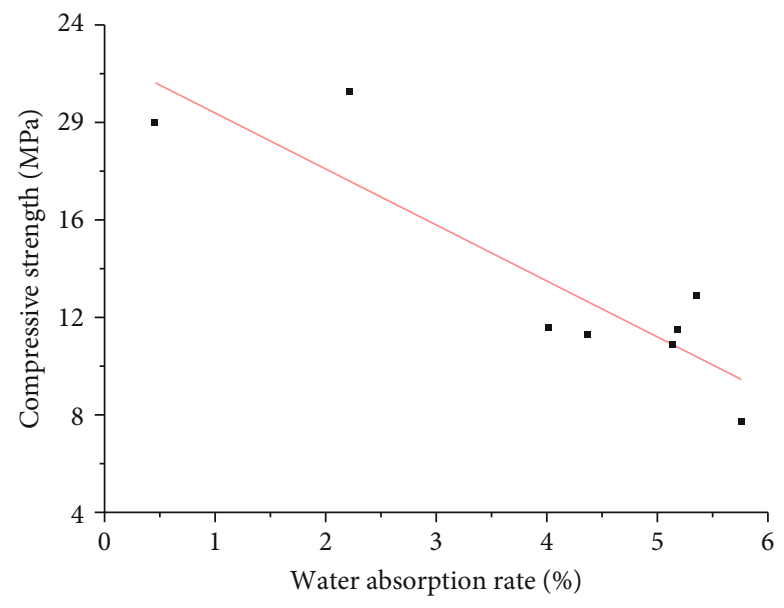

- Measured values

Fitting curve $R^{2}=0.76$

FIGURE 25: Relationship between the compressive strength of siltstone and water absorption of rock samples.

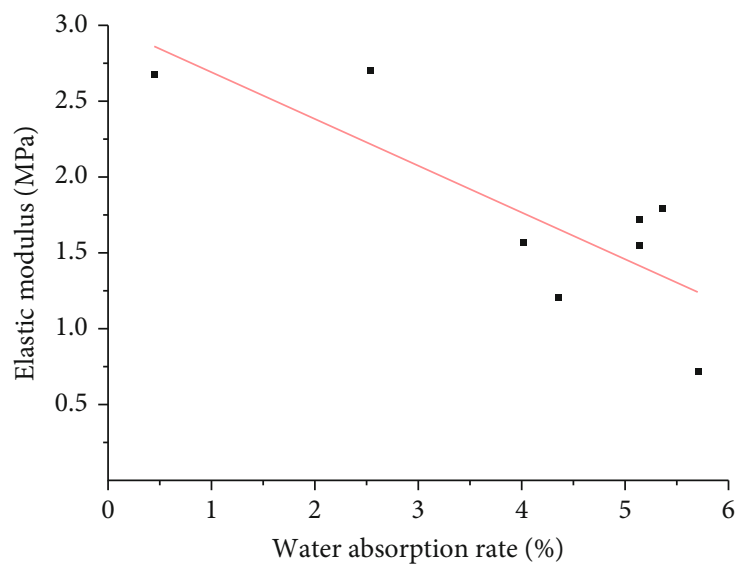

- Measured values

Fitting curve $R^{2}=0.61$

Figure 26: Relationship between the elastic modulus and water absorption of siltstone. 
TABLE 4: Design of environmental parameters of aqueous gaseous water adsorption.

\begin{tabular}{lcrr}
\hline Environment & Characteristics & $\mathrm{T} /{ }^{\circ} \mathrm{C}$ & $\mathrm{W} / \%$ \\
\hline Spring & $\mathrm{T} \uparrow, \mathrm{W} \downarrow$ & $10-20$ & $30-50$ \\
Summer & Hot and humid environment & $30-40$ & $60-90$ \\
Autumn & $\mathrm{T} \downarrow, \mathrm{W} \downarrow$ & $10-20$ & 30 \\
Winter & $\mathrm{T} \downarrow, \mathrm{W} \uparrow$ & -8 & $30-60$ \\
Inside the hole $(>2.5 \mathrm{~m})$ & $\mathrm{T}, \mathrm{W}$ constant of the whole year & $10-20$ & $90-100$ \\
\hline
\end{tabular}

$\mathrm{T}$ refers to temperature; $\mathrm{W}$ refers to humidity.

TABLE 5: Basic parameters of the specimens.

\begin{tabular}{lcccc}
\hline Numbering & Natural quality/g & Diameter/mm & Height/mm & Natural density/g.cm $^{-3}$ \\
\hline $6-2$ & 231.57 & 49.26 & 76.52 & 1.59 \\
8-2 & 278.51 & 48.80 & 91.68 & 1.62 \\
N9-2 & 323.79 & 49.32 & 106.48 & 1.59 \\
N23-1 & 337.5 & 48.82 & 103.16 & 1.75 \\
N1 & 265.36 & 49.52 & 79.82 & 1.73 \\
N3-1 & 163.01 & 49.02 & 52.86 & 1.64 \\
N6-3 & 202.36 & 48.68 & 67.68 & 1.61 \\
N17-1 & 226.56 & 49.90 & 75.12 & 1.54 \\
\hline
\end{tabular}

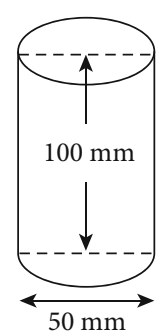

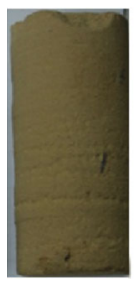

N6-2

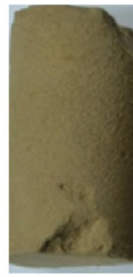

N8-2
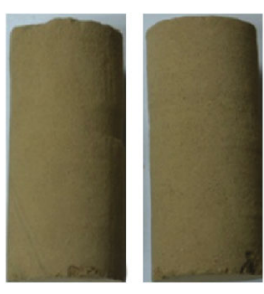

N21-1
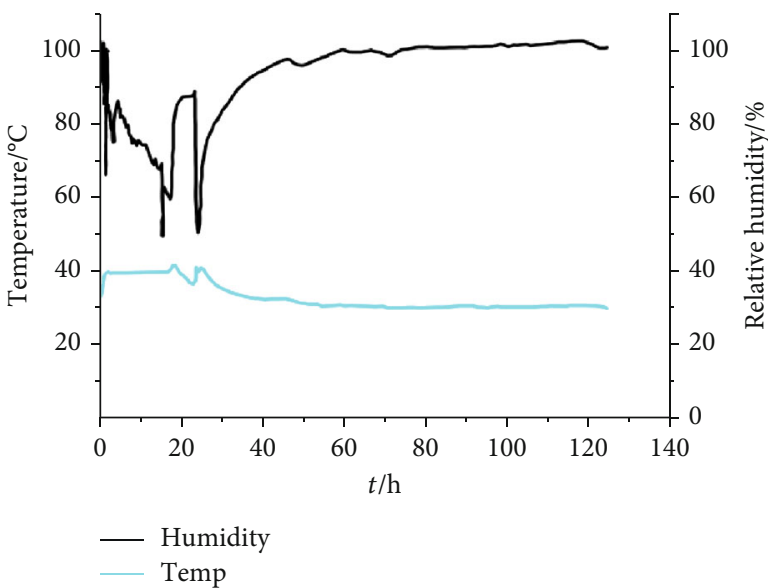

(a) Sample specimens

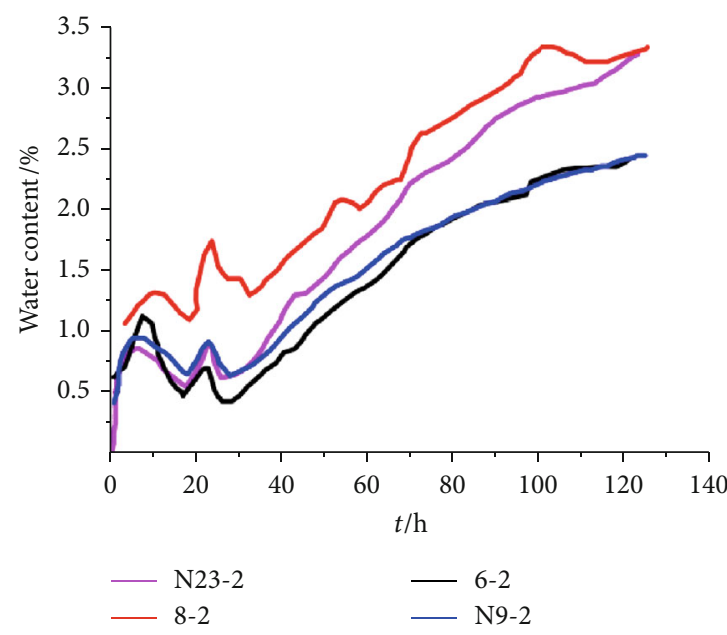

(c) Test curve of sample

Figure 27: Gaseous water adsorption experiment of mudstone in Mogao Grottoes in the summer in Group I. 


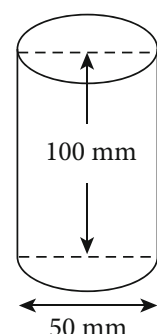

$50 \mathrm{~mm}$

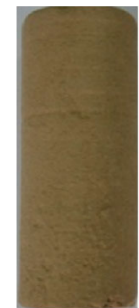

$\mathrm{N} 1$

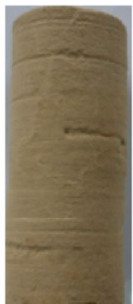

N3-1

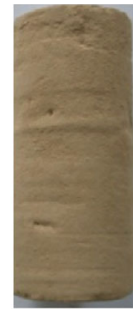

N6-3

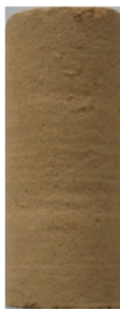

N17-1

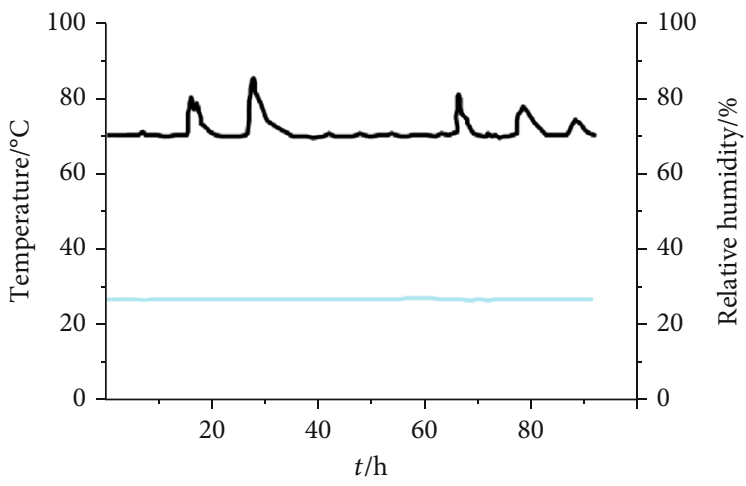

Temperature

- Humidity

(a) Sample specimen

(b) Experimental environment parameters (temperature, $28^{\circ} \mathrm{C}$; humidity, $70 \%$ )

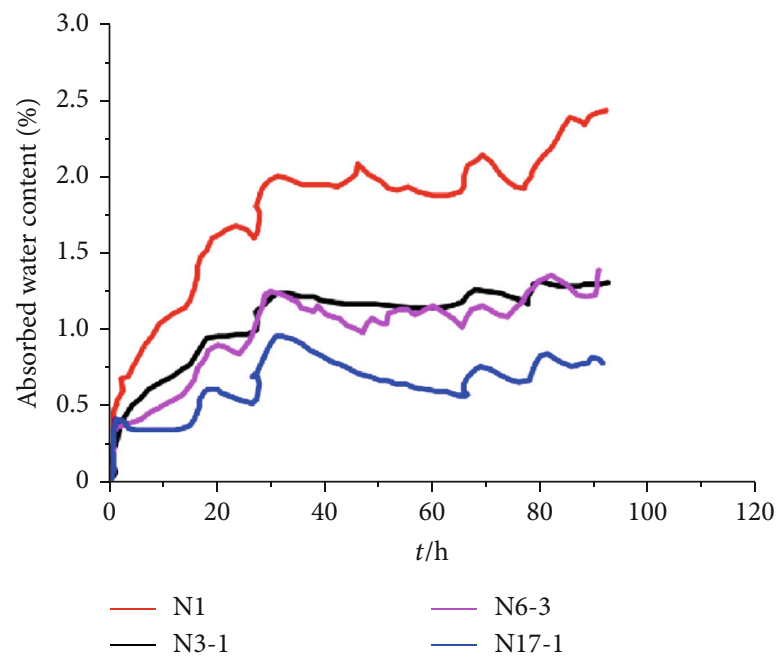

(c) Test curve of samples

FIGURE 28: Gaseous water adsorption experiment of the mudstone samples from Mogao Grottoes in the summer in Group II specimens.

the equilibrium, the increase in the sample's adsorption mass also tends to be stable, and the experiment was carried for $129 \mathrm{~h}$

The set temperature and humidity were $28^{\circ} \mathrm{C}$ and $70 \%$, respectively. For the second set of experiments, the environmental parameter curves and experimental curves are shown in Figure 28, and the experiment duration was $90 \mathrm{~h}$.

(2) Experimental Study on the Adsorption of Aqueous Gaseous Water by the Mudstone Samples Selected from Mogao Grottoes in Winter. On the account of reaching the freezing point at temperature less than zero, the sample was subjected to the winter simulation experiment, resulting in the freezing of water in the tank in the equipment. In order to prevent the container from swelling and the humidification equipment from damage, the humidity was kept constant, and the experimental temperature was controlled within $-10^{\circ} \mathrm{C}$ during the experiment. The experiment lasted for $120 \mathrm{~h}$. The experimental results are shown in Figure 29. The adsorption amount of the sam- ple could be less than $0.8 \mathrm{~g}$, confirming that the adsorption weight gain of the sample was not obvious in the low-temperature environment.

The environmental analysis process indicated that constant temperature and comparatively high relative humidity matched the environmental monitoring results in the hole of the support body (surrounding rock) of the murals in Dunhuang Mogao Grottoes. Among them, when the drilling depth exceeds $2.5 \mathrm{~m}$, the temperature inside the hole was constant throughout the four seasons, and the relative humidity was stable at $100 \%$.

In situ hydrological gaseous water adsorption experiment was carried out for the samples. A total of eight specimens were selected, and four specimens were put in one group for testing. The four mudstone specimens in the first group were numbered as N2-2, N5-1, N10-1, and N22-1. The second group of specimens has two lithologies, namely, mudstone and siltstone. The specimens are numbered S14, S171, 11-1, and 21-1. The basic parameters of the specimens are listed in Table 6. 


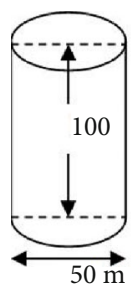

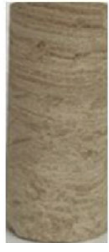

$1 \#$

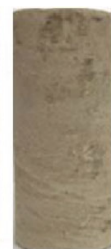

$2 \#$

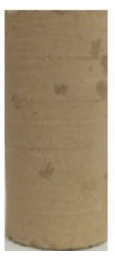

$3 \#$

4\#

(a) Sample specimens

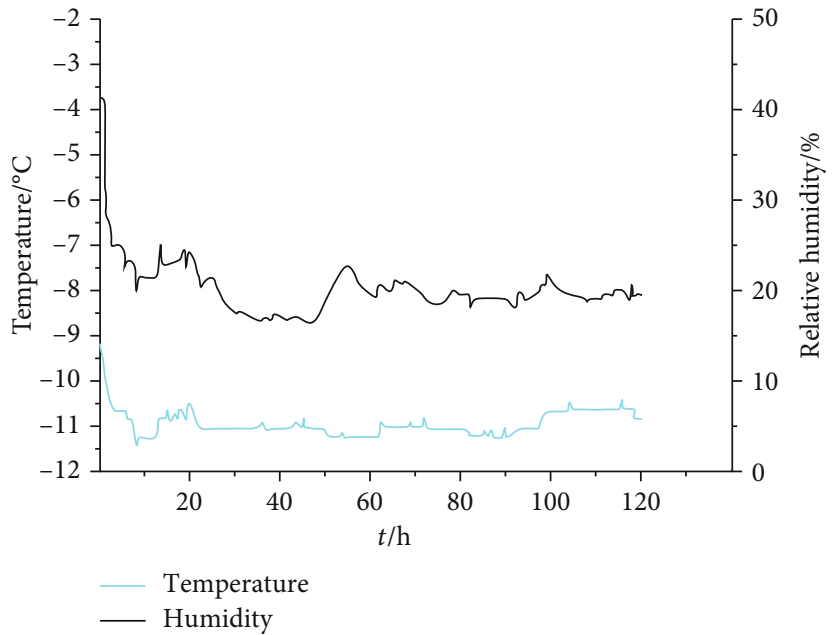

(b) Experimental environment parameters (temperature, $-10^{\circ} \mathrm{C}$; humidity, $30 \%$ )

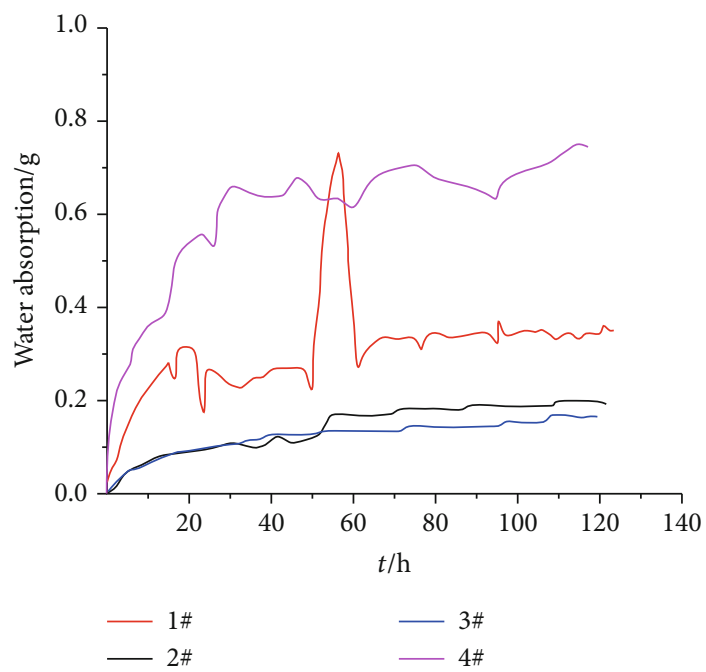

(c) Test curve of samples

FIGURE 29: Gaseous water adsorption experiment of the mudstone samples from Mogao Grottoes in the summer in Group III.

TABLE 6: Basic parameters of the specimens.

\begin{tabular}{|c|c|c|c|c|}
\hline Numbering & Natural quality/g & Diameter/mm & Height/mm & Natural density/g.cm ${ }^{-3}$ \\
\hline N2-2 & 337.11 & 49.02 & 108 & 1.63 \\
\hline N5-1 & 305.61 & 49.00 & 100 & 1.62 \\
\hline N10-1 & 308.01 & 49.20 & 107.6 & 1.39 \\
\hline N22-1 & 363.69 & 48.96 & 110 & 1.75 \\
\hline S14 & 469.33 & 49.88 & 108.02 & 2.28 \\
\hline S17-1 & 477.66 & 49.28 & 108.10 & 2.31 \\
\hline $11-1$ & 338.7 & 48.90 & 103.4 & 1.74 \\
\hline $21-1$ & 361.78 & 49.84 & 112.68 & 1.69 \\
\hline
\end{tabular}

The first set of simulation was carried out under the following conditions: environment temperature, $18^{\circ} \mathrm{C}$; relative humidity, 90\%; and experimental duration, $195 \mathrm{~h}$. The balance curve of the experimental environment parameters is shown in Figure 30. The analysis shows that during the experiment, the temperature and humidity remained constant, and after entering the equilibrium, the increase in the adsorption mass of the sample also tended to be stable. 

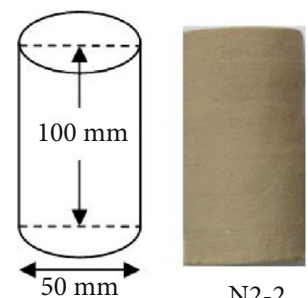

N2-2

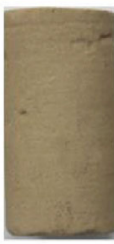

N5-1

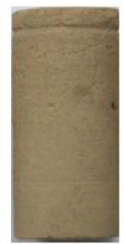

N10-2 N22-1

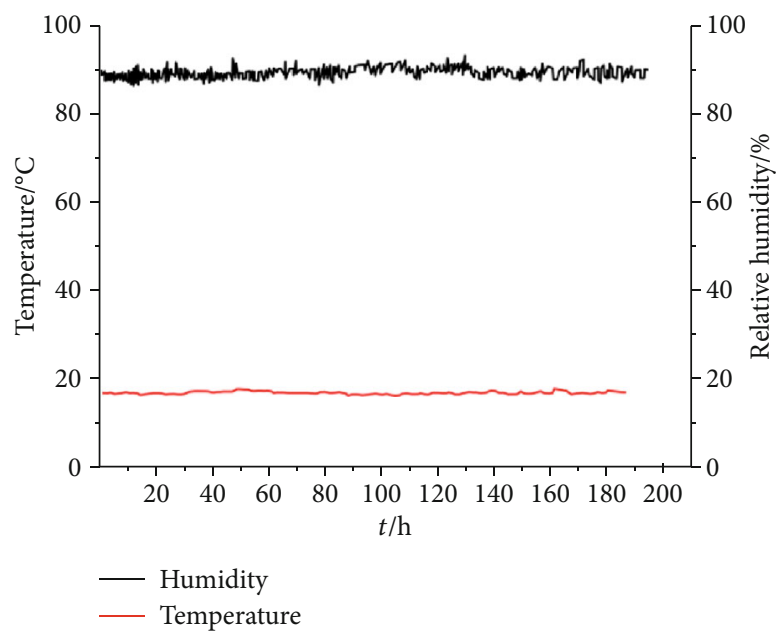

(a) Sample specimen

(b) Experimental environment parameters (temperature, $18^{\circ} \mathrm{C}$; humidity, $90 \%$ )

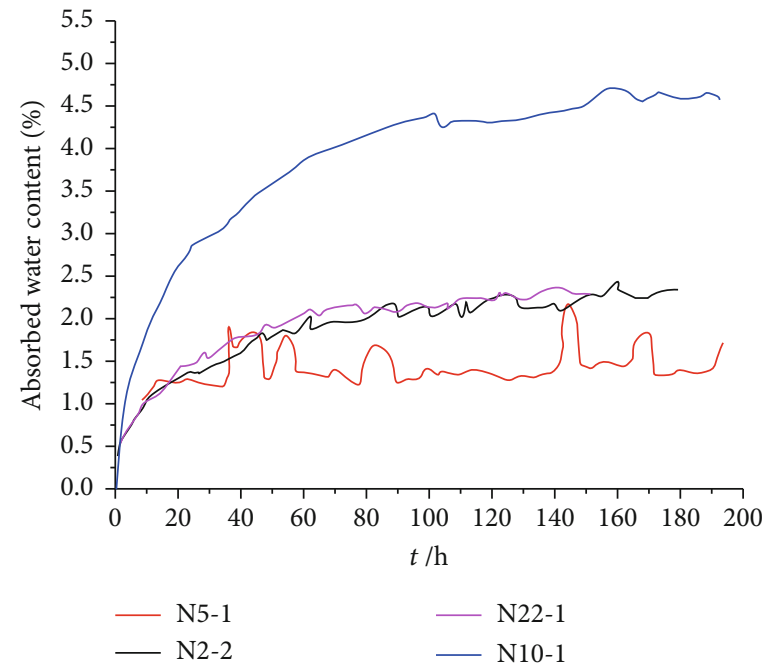

(c) Test curve of samples

FIGURE 30: Simulation experiment of the surrounding rock wall of mudstone supporting body in Mogao Grottoes.

The second set of experiments was performed for $170 \mathrm{~h}$ at a temperature of $20^{\circ} \mathrm{C}$ and a relative humidity of 95 . The environmental parameter curve and the experimental curve are shown in Figure 31. The analysis shows that during the experiment, the temperature and humidity were kept constant, and the adsorption capacity of mudstone samples for gaseous water was greater than that of siltstone samples.

\section{Conclusion}

The intelligent testing system of liquid and gaseous water in soft rock hydrology was developed based on the adsorption of liquid and gaseous water in Dunhuang Grotto rock samples and the softening test of the strength of adsorption of liquid water on rock samples.

The analysis of the curve of liquid water absorption without pressure for the black sandstone samples indicates that the amount of water absorption increased rapidly at the ini- tial stage, then increased moderately, and finally tended to be stable.

The strength softening test analysis of the siltstone samples under no-pressure water absorption conditions shows that the water absorption rate changes with the water absorption time. The analysis of the sample parameters such as compressive strength and elastic modulus shows that with increasing water absorption, the compressive strength and elastic modulus of the sample decreased linearly.

According to the investigation results of the on-site environment combined with the indoor environmental parameters to simulate rock sample for the adsorption of gaseous water, the analysis shows the same results for all the seasons. The characteristics of adsorbed gaseous water in the lithologic rock samples are quite different, and the adsorption characteristics of rock samples with different lithologies in the same season are also quite different. 


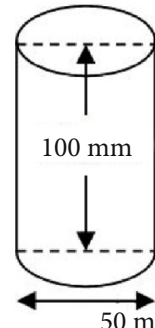

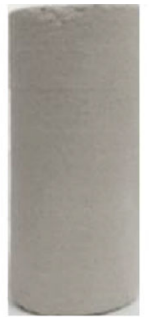

S14

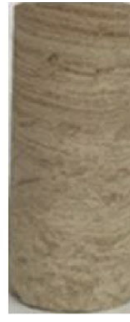

S17-1

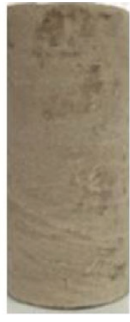

11-1

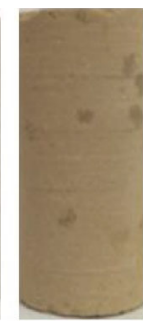

21-1 (a) Sample specimens

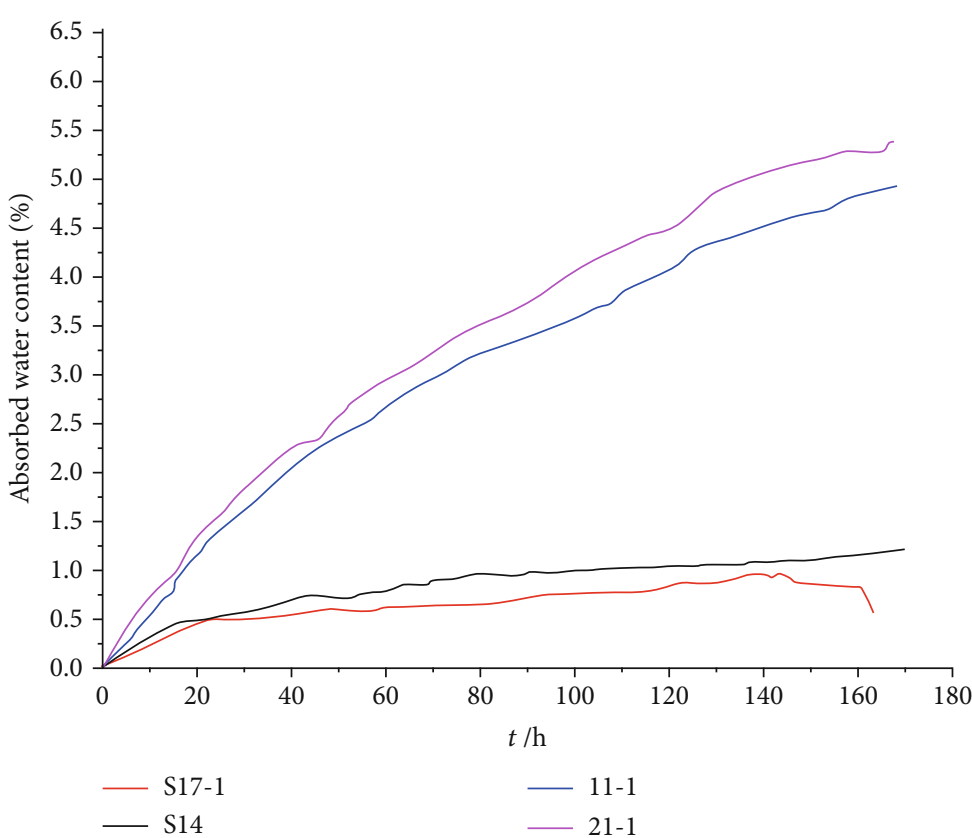

(c) Test curve of sample

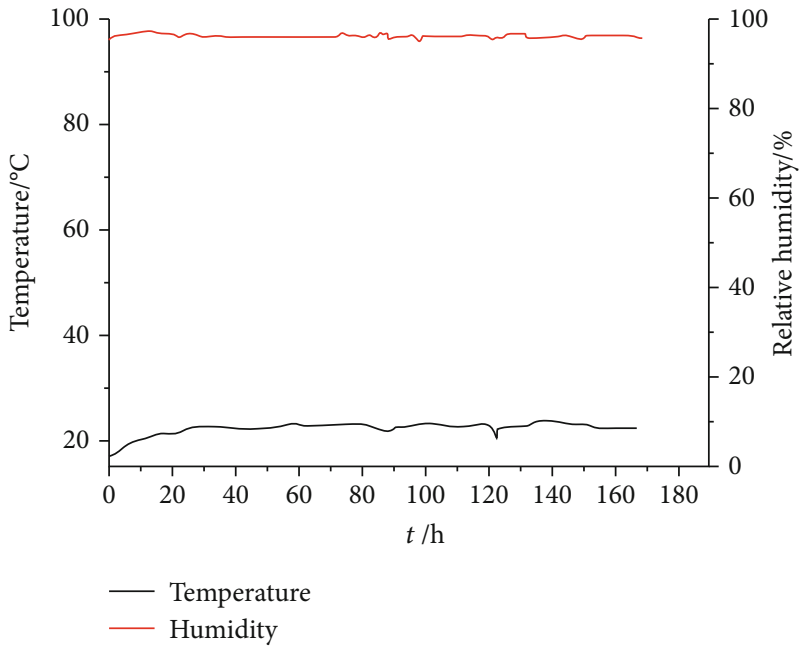

(b) Experimental environment parameters (temperature, $20^{\circ} \mathrm{C}$; humidity, $95 \%$ )

FIGURE 31: Simulation experiment of surrounding rock wall of mudstone supporting body in Mogao Grottoes.

\section{Data Availability}

The data used to support the findings of this study are available from the corresponding author upon request.

\section{Conflicts of Interest}

No conflict of interest exists in the submission of this manuscript. We would like to declare that the described work was an original research that has not been previously published.

\section{Authors' Contributions}

The manuscript was approved by all authors for publication.

\section{Acknowledgments}

This work was supported by the Key Research and Development Project of Zhejiang Province (Grant No: 2019C03104). Academician Manchao He provided helpful comments on the current manuscript.

\section{References}

[1] H. Liu, X. Wang, and Q. Guo, "Field testing study on the rainfall thresholds and prone areas of sandstone slope erosion at Mogao Grottoes, Dunhuang," Environmental Monitoring and Assessment, vol. 191, no. 12, p. 755, 2019.

[2] D. Liu, Z. Gu, R. Liang et al., "Impacts of pore-throat system on fractal characterization of tight sandstones," Geofluids, vol. 2020, Article ID 4941501, 17 pages, 2020. 
[3] X. D. Wang, H. Y. Zhang, and Q. L. Guo, "Weathering characterization and conservation treatment of cliff at Mogao Grottoes," Chinese Journal of Rock Mechanics and Engineering, vol. 28, no. 5, pp. 1055-1063, 2009.

[4] J. Wang, Y. Zhang, Z. Qin, S. G. Song, and P. Lin, “Analysis method of water inrush for tunnels with damaged waterresisting rock mass based on finite element method-smooth particle hydrodynamics coupling," Computers and Geotechnics, vol. 126, article 103725, 2020.

[5] S. C. Hu, Y. L. Tan, H. Zhou et al., "Anisotropic modeling of layered rocks incorporating planes of weakness and volumetric stress," Energy Science \& Engineering, vol. 8, no. 3, pp. 789803, 2020.

[6] J. Xu, A. Haque, W. Gong et al., "Experimental study on the bearing mechanisms of rock-socketed piles in soft rock based on micro X-ray CT analysis," Rock Mechanics and Rock Engineering, vol. 53, no. 8, pp. 3395-3416, 2020.

[7] O. Allegretti, M. De Vincenzi, L. Uzielli, and P. Dionisi-Vici, "Long-term hygromechanical monitoring of wooden objects of art (WOA): a tool for preventive conservation," Journal of Cultural Heritage, vol. 14, no. 3, pp. e161-e164, 2013.

[8] D. Z. Ren, D. S. Zhou, D. K. Liu, F. Dong, S. Ma, and H. Huang, "Formation mechanism of the upper Triassic Yanchang Formation tight sandstone reservoir in Ordos Basin-Take Chang 6 reservoir in Jiyuan oil field as an example," Journal of Petroleum Science and Engineering, vol. 178, pp. 497-505, 2019.

[9] J. T. Chen, J. H. Zhao, S. C. Zhang, Y. Zhang, F. Yang, and M. Li, "An experimental and analytical research on the evolution of mining cracks in deep floor rock mass," Pure and Applied Geophysics, 2020.

[10] G. Feng, Y. Kang, X. C. Wang, Y. Hu, and X. Li, "Investigation on the failure characteristics and fracture classification of shale under brazilian test conditions," Rock Mechanics and Rock Engineering, vol. 53, no. 7, pp. 3325-3340, 2020.

[11] M. Hoyos, V. Soler, J. C. Canaveras, S. Sanchez-Moral, and E. Sanz-Rubio, "Microclimatic characterization of a karstic cave: human impact on microenvironmental parameters of a prehistoric rock art cave (Candamo Cave, northern Spain)," Environmental Geology, vol. 33, no. 4, pp. 231-242, 1998.

[12] G. Feng, X. C. Wang, M. Wang, and Y. Kang, "Experimental investigation of thermal cycling effect on fracture characteristics of granite in a geothermal-energy reservoir," Engineering Fracture Mechanics, vol. 235, article 107180, 2020.

[13] X. Wang, C. Liu, S. Chen, L. Chen, K. Li, and N. Liu, "Impact of coal sector's de-capacity policy on coal price," Applied Energy, vol. 265, article 114802, 2020.

[14] Y. D. Zhang, Environmental monitoring of Mogao Grottoes in Dunhuang and its impact on mural diseases, Beijing University of Chemical Technology, 2015.

[15] J. J. Qu, M. Q. Zhang, and W. M. Zhang, "A preliminary study on weathering process of salt in rock body at Mogao Grottoes Dunhung," Scientia Geographica Sinica, vol. 15, no. 2, pp. 182$187,1995$.

[16] C. X. Wang, B. T. Shen, J. T. Chen et al.et al., "Compression characteristics of filling gangue and simulation of mining with gangue backfilling: an experimental investigation," Geomechanics and Engineering, vol. 20, no. 6, pp. 485-495, 2020.

[17] E. Kotulanová, P. Bezdička, D. Hradil, J. Hradilová, S. Švarcová, and T. Grygar, "Degradation of lead-based pigments by salt solutions," Journal of Cultural Heritage, vol. 10, no. 3, pp. 367-378, 2009.
[18] D. Benavente, S. Sanchez-Moral, A. Fernandez-Cortes, J. C. Cañaveras, J. Elez, and C. Saiz-Jimenez, "Salt damage and microclimate in the Postumius Tomb, Roman necropolis of Carmona, Spain," Environmental Earth Sciences, vol. 63, no. 7-8, pp. 1529-1543, 2011.

[19] L. S. Tang and S. J. Wang, "Research and development of the mechanical effect of water-rock and soil chemistry," Journal of Engineering Geology, vol. 8, no. S, pp. 395-403, 2000.

[20] H. Huang, T. Babadagli, X. Chen, H. Li, and Y. Zhang, "Performance comparison of novel chemical agents for mitigating water-blocking problem in tight gas sandstones," SPE Reservoir Evaluation \& Engineering, 2020.

[21] J. Xu, G. Dai, W. Gong, Q. Zhang, A. Haque, and R. P. Gamage, "A review of research on the shaft resistance of rock-socketed piles," Acta Geotechnica, 2020.

[22] S. L. Yang, X. D. Wang, and Q. L. guo, "Preliminary analysis of moisture distribution in cliff rocks of the Mogao Grottoes in Dunhuang," Hydrogeology and Engineering Geology, vol. 5, pp. 94-97, 2009.

[23] H. L. Liu, X. D. Wang, and M. Q. Zhang, "Research on the characteristics of rainfall distribution and infiltration in Dunhuang Mogao Grottoes," Sciences of Conservation and Archaeology, vol. 28, no. 2, pp. 32-36, 2016.

[24] H. Y. Pan, D. W. Yin, N. Jiang, and Z. G. Xia, "Crack initiation behaviors of granite specimens containing crossing-doubleflaws with different lengths under uniaxial loading," Advances in Civil Engineering, vol. 2020, Article ID 8871335, 13 pages, 2020.

[25] C. Zhu, M. He, M. Karakus, X. Cui, and Z. Tao, "Investigating toppling failure mechanism of anti-dip layered slope due to excavation by physical modelling," Rock Mechanics and Rock Engineering, 2020.

[26] J. Rutqvist, D. Barr, R. Datta et al., "Coupled thermal-hydrological-mechanical analyses of the Yucca Mountain Drift Scale Test-comparison of field measurements to predictions of four different numerical models," International Journal of Rock Mechanics and Mining Sciences, vol. 42, no. 5-6, pp. 680-697, 2005.

[27] J. Forbes, "Air temperature and relative humidity study: Torgac Cave, New Mexico," Journal of Caves and Karst Studies, vol. 60 , pp. 27-32, 1998.

[28] A. Athanassiou, A. E. Hill, T. Fourrier, L. Burgio, and R. J. H. Clark, "The effects of UV laser light radiation on artists' pigments," Journal of Cultural Heritage, vol. 1, pp. S209-S213, 2000.

[29] C. R. de Freitas, R. N. Littlbjohn, T. S. Clarkson, and I. S. Kristament, "Cave climate: assessment of airflow and ventilation," International Journal of Climatology, vol. 2, no. 4, pp. 383-397, 1982.

[30] S. Miura, T. Nishiura, S. Li, and Y. J. Zhang, "Climate in the Mogao Cave 1," Science for Conservation, vol. 29, pp. 1-7, 1990. 